NBER WORKING PAPER SERIES

\title{
THE ECONOMIC IMPACTS OF CLIMATE CHANGE: EVIDENCE FROM AGRICULTURAL PROFITS AND RANDOM FLUCTUATIONS IN WEATHER
}

\author{
Olivier Deschenes \\ Michael Greenstone \\ Working Paper 10663 \\ http://www.nber.org/papers/w10663
NATIONAL BUREAU OF ECONOMIC RESEARCH 1050 Massachusetts Avenue
Cambridge, MA 02138

August 2004

\begin{abstract}
We thank David Bradford for initiating a conversation that ultimately led to this paper. Hoyt Bleakley, Tim Conley, Enrico Moretti, Marc Nerlove, and Wolfram Schlenker provided insightful comments. We are also grateful for comments from seminar participants at Maryland, Yale, the NBER Environmental Economics Summer Institute, and the "Conference on Spatial and Social Interactions in Economics" at the University of California-Santa Barbara. Anand Dash, Barrett Kirwan, Nick Nagle, and William Young, provided outstanding research assistance. Finally, we are indebted to Shawn Bucholtz at the United States Department of Agriculture for generously generating the weather data. Greenstone acknowledges generous funding from the American Bar Foundation. The views expressed herein are those of the author(s) and not necessarily those of the National Bureau of Economic Research.
\end{abstract}

C2004 by Olivier Deschenes and Michael Greenstone. All rights reserved. Short sections of text, not to exceed two paragraphs, may be quoted without explicit permission provided that full credit, including (C) notice, is given to the source. 
The Economic Impacts of Climate Change: Evidence from Agricultural Profits and Random Fluctuations in Weather

Olivier Deschenes and Michael Greenstone

NBER Working Paper No. 10663

August 2004, Revised February 2006

JEL No. Q50, Q12, C23, Q54, Q51

\section{ABSTRACT}

This paper measures the economic impact of climate change on US agricultural land. We replicate the previous literature's implementation of the hedonic approach and find that it produces estimates of the effect of climate change that are very sensitive to decisions about the appropriate control variables, sample and weighting. We find estimates of the benchmark doubling of greenhouse gases on agricultural land values that range from a decline of $\$ 420$ billion (1997\$) to an increase of $\$ 265$ billion, or $-30 \%$ to $19 \%$. Despite its theoretical appeal, the wide variability of these estimates suggests that the hedonic method may be unreliable in this setting.

In light of the potential importance of climate change, this paper proposes a new strategy to determine its economic impact. We estimate the effect of weather on farm profits, conditional on county and state by year fixed effects, so the weather parameters are identified from the presumably random variation in weather across counties within states. The results suggest that the benchmark change in climate would reduce the value of agricultural land by $\$ 40$ to $\$ 80$ billion, or $-3 \%$ to $-6 \%$, but the null of zero effect cannot be rejected. In contrast to the hedonic approach, these results are robust to changes in specification. Since farmers can engage in a more extensive set of adaptations in response to permanent climate changes, this estimate is likely downwards biased, relative to the preferred long run effect. Together the point estimates and sign of the likely bias contradict the popular view that climate change will have substantial negative welfare consequences for the US agricultural sector.

Olivier Deschenes

Department of Economics

2127 North Hall

University of California

Santa Barbara, CA 93106-9210

olivier@econ.ucsb.edu
Michael Greenstone

MIT

Department of Economics

50 Memorial Drive, E52

Cambridge, MA 02142

and NBER

mgreenst@mit.edu 


\section{Introduction}

There is a growing consensus that emissions of greenhouse gases due to human activity will lead to higher temperatures and increased precipitation. It is thought that these changes in climate will impact economic well being. Since temperature and precipitation are direct inputs in agricultural production, many believe that the largest effects will be in this sector. Previous research on climate change is inconclusive about the sign and magnitude of its effect on the value of US agricultural land (see, for example, Adams 1989; Mendelsohn, Nordhaus, and Shaw 1994 and 1999; Kelly, Kolstad, and Mitchell 2005; Schlenker, Hanemann, and Fisher 2005a, b).

Most prior research employs either the production function or hedonic approach to estimate the effect of climate change. ${ }^{1}$ Due to its experimental design, the production function approach provides estimates of the effect of weather on the yields of specific crops that are purged of bias due to determinants of agricultural output that are beyond farmers' control (e.g., soil quality). Its disadvantage is that these experimental estimates do not account for the full range of compensatory responses to changes in weather made by profit maximizing farmers. For example in response to a change in climate, farmers may alter their use of fertilizers, change their mix of crops, or even decide to use their farmland for another activity (e.g., a housing complex). Since farmer adaptations are completely constrained in the production function approach, it is likely to produce estimates of climate change that are biased downwards.

The hedonic approach attempts to measure directly the effect of climate on land values. Its clear advantage is that if land markets are operating properly, prices will reflect the present discounted value of land rents into the infinite future. In principle, this approach accounts for the full range of farmer adaptations. The limitation is that the validity of this approach requires consistent estimation of the effect of climate on land values. Since at least the classic Hoch (1958 and 1962) and Mundlak (1961) papers, it has been recognized that unmeasured characteristics (e.g., soil quality) are an important determinant of output and land values in agricultural settings. ${ }^{2}$ Consequently, the hedonic approach may confound climate with other factors and the sign and magnitude of the resulting omitted variables bias is unknown.

In light of the importance of the question, this paper proposes a new strategy to estimate the impact of climate change on the agricultural sector. The idea is to exploit the presumably random yearto-year variation in temperature and precipitation to estimate their effect on agricultural profits to assess

\footnotetext{
${ }^{1}$ Throughout "weather" refers to the state of the atmosphere at a given time and place, with respect to variables such as temperature and precipitation. "Climate" or "climate normals" refers to a location's weather averaged over long periods of time.

${ }^{2}$ Mundlak focused on heterogeneity in the skills of farmers, however he recognized that there are numerous other sources of farm-specific effects. In Mundlak (2001), he writes, "Other sources of farm-specific effects are differences in land quality, micro-climate, and so on" (p. 9).
} 
whether on average US farm profits are higher or lower in warmer and wetter years. We then multiply the estimated impacts of temperature and precipitation on agricultural profits by the predicted change in climate to infer the economic impact.

Specifically, we use a county-level panel data file constructed from the Censuses of Agriculture to estimate the effect of weather on agricultural profits, conditional on county and state by year fixed effects. Thus, the weather parameters are identified from the county-specific deviations in weather about the county averages after adjustment for shocks common to all counties in a state. Put another way, our estimates are identified from comparisons of counties within the same state that had positive weather shocks with ones that had negative weather shocks, after accounting for their average weather realization.

This variation is presumed to be orthogonal to unobserved determinants of agricultural profits, so it offers a possible solution to the omitted variables bias problems that appear to plague the hedonic approach. The primary limitation of the approach is that farmers cannot implement the full range of adaptations in response to a single year's weather realization. Consequently, its estimates of the impact of climate change may be biased downwards.

Using long-run climate change predictions from the Hadley 2 Model, the preferred estimates indicate that climate change will lead to a $\$ 1.1$ billion (2002\$) or 3.4\% increase in annual agricultural sector profits. The $95 \%$ confidence interval ranges from $-\$ 1.8$ billion to $\$ 4.0$ billion so large negative or positive effects are unlikely. The basic finding of an economically and statistically small effect is robust to a wide variety of specification checks including adjustment for the rich set of available controls, modeling temperature and precipitation flexibly, estimating separate regression equations for each state, and implementing a procedure that minimizes the influence of outliers. Additionally, the analysis indicates that the predicted increases in temperature and precipitation will have virtually no effect on yields among the most important crops (i.e., corn for grain, soybeans, and wheat). These crop yield findings suggest that the small effect on profits is not due to short-run price increases.

Although the overall effect is small, there is considerable heterogeneity across the country. The most striking finding is that California will be substantially harmed by climate change. Its predicted loss in agricultural profits is $\$ 2.4$ billion and this is nearly $50 \%$ of current annual profits in California. Colorado (-\$610 million) and Oklahoma (-\$580 million) are also predicted to have big losses, while the two biggest winners are Pennsylvania (\$570 million) and South Dakota (\$540 million). It is important to note that these state-level estimates are demanding of the data and therefore less precise than is optimal.

The paper also re-examines the hedonic approach that is predominant in the previous literature. There are two important findings. First, the observable determinants of land prices are poorly balanced across quartiles of the long run temperature and precipitation averages. This means that functional form assumptions are important in this approach. Further, it may suggest that unobserved variables are likely 
to covary with climate.

Second, we implement the hedonic approach using all the available data on agricultural land values. We find that estimates of the effect of the benchmark doubling of greenhouse gasses on the value of agricultural land range from $-\$ 200$ billion (1997\$) to $\$ 320$ billion (or $-24 \%$ to $39 \%$ ), which is an even wider range than has been noted in the previous literature. This variation in predicted impacts results from seemingly minor decisions about the appropriate control variables, sample, and weighting. Despite its theoretical appeal, we conclude that the hedonic method may be unreliable in this setting. ${ }^{3}$

The analysis is conducted with the most detailed and comprehensive data available on agricultural production, soil quality, climate, and weather. The agricultural land values, profits and production data is derived from the 1978, 1982, 1987, 1992, 1997, and 2002 Censuses of Agriculture. The soil quality data comes from the National Resource Inventory data files from the same years. The climate and weather data are derived from the Parameter-elevation Regressions on Independent Slopes Model (PRISM). This model generates estimates of precipitation and temperature at small geographic scales, based on observations from the more than 8,000 weather stations in the National Climatic Data Center's (NCDC) Summary of the Month Cooperative Files during the 1970-2000 period. The PRISM data are used by NASA, the Weather Channel, and almost all other professional weather services. We also use daily measurements of temperature from the Summary of the Day Data Files of the NCDC. The predicted changes in state-level climates come from the Hadley Centre's $2^{\text {nd }}$ Climate Model

The paper proceeds as follows. Section I motivates our approach and discusses why it may be an appealing alternative to the hedonic and production function approaches. Section II describes the data sources and provides some summary statistics. Section III presents the econometric approach and Section IV describes the results. Section $\mathrm{V}$ assesses the magnitude of our estimates of the effect of climate change and discusses a number of important caveats to the analysis. Section VI concludes the paper.

\section{Motivation and Conceptual Framework}

This paper attempts to develop a reliable estimate of the consequences of global climate change in the US agricultural sector. Most previous research on this topic employs either the production function or hedonic approach to estimate the effect of climate change. Here, we discuss these methods' strengths and weaknesses and motivate our alternative approach.

\section{A. Production Function and Hedonic Approaches to Valuing Climate Change}


The production function approach relies on experimental evidence of the effect of temperature and precipitation on agricultural yields. The appealing feature of the experimental design is that it provides estimates of the effect of weather on the yields of specific crops that are purged of bias due to determinants of agricultural output that are beyond farmers' control (e.g., soil quality). Consequently, it is straightforward to use the results of these experiments to estimate the impacts of a given change in temperature or precipitation.

Its disadvantage is that the experimental estimates are obtained in a laboratory setting and do not account for profit maximizing farmers' compensatory responses to changes in climate. As an illustration, consider a permanent and unexpected decline in precipitation. In the short run, farmers may respond by increasing the flow of irrigated water or altering fertilizer usage to mitigate the loss in rainfall. In the medium run, farmers can choose to plant different crops that require less precipitation. And in the long run, farmers can convert their land into housing developments, golf courses, or some other purpose. Since even short run farmer adaptations are not allowed in the production function approach, it produces estimates of climate change that are downward biased. For this reason, it is sometimes referred to as the "dumb-farmer scenario."

In an influential paper, Mendelsohn, Nordhaus, and Shaw (MNS) proposed the hedonic approach as a solution to the production function's shortcomings (MNS 1994). The hedonic method aims to measure the impact of climate change by directly estimating the effect of temperature and precipitation on the value of agricultural land. Its appeal is that if land markets are operating properly, prices will reflect the present discounted value of land rents into the infinite future. MNS write the following about the hedonic approach:

Instead of studying yields of specific crops, we examine how climate in different places affects the net rent or value of farmland. By directly measuring farm prices or revenues, we account for the direct impacts of climate on yields of different crops as well as the indirect substitution of different inputs, introduction of different activities, and other potential adaptations to different climates (p. 755, 1994).

Thus the hedonic approach promises an estimate of the effect of climate change that accounts for the compensatory behavior that undermines the production function approach.

To successfully implement the hedonic approach, it is necessary to obtain consistent estimates of the independent influence of climate on land values and this requires that all unobserved determinants of land values are orthogonal to climate. ${ }^{4}$ We demonstrate below that temperature and precipitation normals

\footnotetext{
${ }^{3}$ This finding is consistent with recent research indicating that cross-sectional hedonic equations are misspecified in a variety of contexts (Black 1999; Black and Kneisner 2003; Chay and Greenstone 2005; Greenstone and Gallagher 2005).

${ }^{4}$ In Rosen's (1974) classical derivation of the hedonic model, the estimates of the effect of climate on land prices can only be used to value marginal changes in climate. It is necessary to estimate technology parameters to value non-marginal changes. Rosen suggests doing this in a second step. Ekeland, Heckman, and Nesheim (2004) outline
} 
covary with soil characteristics, population density, per capita income, and latitude. Moreover, Schlenker, Hanemann, and Fisher (SHF) show that the availability of irrigated water also covaries with climate (SHF 2005a). This means that functional form assumptions are important in the hedonic approach and may imply that unobserved variables are likely to covary with climate. Further, recent research has found that cross-sectional hedonic equations appear to be plagued by omitted variables bias in a variety of settings (Black 1999; Black and Kneisner 2003; Chay and Greenstone 2005; Greenstone and Gallagher 2005). ${ }^{5}$ Overall, it may be reasonable to assume that the cross-sectional hedonic approach confounds the effect of climate with other factors (e.g., soil quality).

This discussion highlights that for different reasons the production function and hedonic approaches are likely to produce biased estimates of the economic impact of climate change. It is impossible to know the magnitude of the biases associated with either approach and in the hedonic case even the sign is unknown.

\section{B.A New Approach to Valuing Climate Change}

In this paper we propose an alternative strategy to estimate the effects of climate change. We use a county-level panel data file constructed from the Censuses of Agriculture to estimate the effect of weather on agricultural profits, conditional on county and state by year fixed effects. Thus, the weather parameters are identified from the county-specific deviations in weather about the county averages after adjustment for shocks common to all counties in a state. This variation is presumed to be orthogonal to unobserved determinants of agricultural profits, so it offers a possible solution to the omitted variables bias problems that appear to plague the hedonic approach.

This approach differs from the hedonic one in a few key ways. First, under an additive separability assumption, its estimated parameters are purged of the influence of all unobserved time invariant factors. Second, it is not feasible to use land values as the dependent variable once the county fixed effects are included. This is because land values reflect long run averages of weather, not annual deviations from these averages, and there is no time variation in such variables.

Third, although the dependent variable is not land values, our approach can be used to approximate the effect of climate change on agricultural land values. Specifically, we estimate how farm profits are affected by increases in temperature and precipitation. We then multiply these estimates by the predicted changes in climate to infer the impact on profits. Since the value of land is equal to the present discounted stream of rental rates, it is straightforward to calculate the change in land values when we

a method to recover these parameters in a single step. MNS implicitly assume that the predicted changes in temperature and precipitation under the benchmark global warming scenario are marginal.

${ }^{5}$ For example, the regression-adjusted associations between wages and many job amenities and housing prices and air pollution are weak and often have a counterintuitive sign (Black and Kneisner 2003; Chay and Greenstone 2005). 
assume the predicted change in profits is permanent and make an assumption about the discount rate.

\section{The Economics of Using Annual Variation in Weather to Infer the Impacts of Climate Change}

There are two economic issues that could undermine the validity of using the relationship between short run variation in weather and farm profits to infer the effects of climate change. The first issue is that short run variation in weather may lead to temporary changes in prices that obscure the true long-run impact of climate change. To see this, consider the following simplified expression for the profits of a representative farmer that is producing a given crop (and is unable to switch crops in response to short run variation in weather):

$$
\pi=\mathrm{p}(\mathrm{q}(\mathrm{w})) \mathrm{q}(\mathrm{w})-\mathrm{c}(\mathrm{q}(\mathrm{w})),
$$

where p, q, and c, denote prices, quantities, and costs, respectively. Prices and total costs are a function of quantities. Importantly, quantities are a function of weather, $w$, because precipitation and temperature directly affect yields.

Since climate change is a permanent phenomenon, we would like to isolate the long run change in profits. Consider how the representative producer's profits respond to a change in weather:

$$
\partial \pi / \partial \mathrm{w}=(\partial \mathrm{p} / \partial \mathrm{q})(\partial \mathrm{q} / \partial \mathrm{w}) \mathrm{q}+(\mathrm{p}-\partial \mathrm{c} / \partial \mathrm{q})(\partial \mathrm{q} / \partial \mathrm{w})
$$

The first term is the change in prices due to the weather shock (through weather's effect on quantities) multiplied by the initial level of quantities. When the change in weather affects output, the first term is likely to differ in the short and long runs. Consider a weather shock that reduces output (e.g., (i.e., $\partial \mathrm{q} / \partial \mathrm{w}<0$ ). In the short run supply is likely to be inelastic due to the lag between planting and harvests, so $(\partial \mathrm{p} / \partial \mathrm{q})_{\text {Short Run }}<0$. This increase in prices helps to mitigate the representative farmer's losses due to the lower production. However, the supply of agricultural goods is more elastic in the long run as other farmers (or even new farmers) will respond to the price change by increasing output. Consequently, it is sensible to assume that $(\partial \mathrm{p} / \partial \mathrm{q})_{\text {Long Run }}>(\partial \mathrm{p} / \partial \mathrm{q})_{\text {Short Run }}$ and is perhaps even equal to zero. The result is that the first term may be positive in the short run but small, or zero in the long run.

The second term in equation (2) is the difference between price and marginal cost multiplied by the change in quantities due to the change in weather. This term measures the change in profits due to the weather-induced change in quantities. It is the long run effect of climate change on agricultural profits (holding constant crop choice), and this is the term that we would like to isolate.

Although our empirical approach relies on short run variation in weather, there are several reasons that it may be reasonable to assume that our estimates are largely purged of the influence of price changes (i.e., the first term in equation (2)). Most importantly, our preferred empirical estimates indicate that the predicted changes in climate will have a statistically and economically small effect on crop yields (i.e., quantities) of the most important crops. This finding undermines much of the basis for concerns 
about short run price changes. Further the preferred econometric model includes a full set of state by year interactions, so it non-parametrically adjusts for all factors that are common across counties within a state by year, such as crop price levels. ${ }^{6}$ Thus, the estimates will not be influenced by changes in state-level agricultural prices. Interestingly, the qualitative results are similar whether we control for year or state by year fixed effects. ${ }^{7}$

The second potential threat to the validity of our approach is that farmers cannot undertake the full range of adaptations in response to a singe year's weather realization. Specifically, permanent climate change might cause them to alter the activities they conduct on their land. For example, they might switch crops because profits would be higher with an alternative crop.

Figure 1 illustrates this issue. Profits per acre are on the y-axis and temperature is on the $x$-axis. For simplicity, we assume that the influence of precipitation and all other exogenous determinants (e.g., soil quality) of profits per acre have been successfully controlled or adjusted for. The Crop 1 and Crop 2 Profit Functions reveal the relationship between profits per acre and temperature when these crops are chosen. It is evident that crop-specific profits vary with temperatures. Further, the profit maximizing crop varies with temperature. For example, Crop 1 maximizes profits between $T_{1}$ and $T_{2}$, Crops 1 and 2 produce identical profits at $T_{2}$ where the profit functions cross (i.e., point $B$ ), and Crop 2 is optimal at temperatures between $\mathrm{T}_{2}$ and $\mathrm{T}_{3}$.

The hedonic equilibrium is denoted as the broken line and it represents the equilibrium relationship between temperature and profits. In the long run when farmers can freely switch crops, they will choose to operate along the hedonic equilibrium because it reveals the crop choices that maximize their profits. It is formed by the regions of each crop's profit function where that crop produces the highest profits over all potential uses of that land.

Consider a permanent increase in temperature from $T_{1}$ to $T_{3}$. If farmers are able to switch production from crop 1 to crop 2, then their profits can be read off the $\mathrm{y}$-axis at point $\mathrm{C}$. However, farmers that are unable to switch crops will earn profits associated with point $C^{\prime}$. Thus, the long-run change in profits is $\mathrm{C}-\mathrm{A}$, but, in the short run, the difference is $\mathrm{C}^{\prime}-\mathrm{A}$, which is a downward biased estimate of the long-run effect. It is noteworthy that if the new temperature is $>=T_{1}$ and $<=T_{2}$, then the

\footnotetext{
${ }^{6}$ If production in individual counties affects the overall price level, which would be the case if a few counties determine crop prices, or there are segmented local (i.e., geographic units smaller than states) markets for agricultural outputs, then this identification strategy will not be able to hold prices constant. We suspect that this is unlikely, because production of the most important crops is spread out across the country and not concentrated in a small number of counties. For example, McLean County, Illinois and Whitman County, Washington are the largest producers of corn and wheat, respectively, but they only account for $0.58 \%$ and $1.39 \%$ of total production of these crops in the US.

${ }^{7}$ We explored whether it was possible to directly control for local prices. The USDA maintains data files on crop prices at the state-level, but unfortunately these data files frequently have missing values and limited geographic
} 
farmer's short-run and long-run profits are equal because the hedonic equilibrium and the crop 1 profit function are identical.

This paper's empirical strategy relies on year-to-year variation in weather and thus it is unlikely that farmers are able to switch crops (or replace farms with golf courses) upon a year's weather realization. The import for the subsequent analysis is that our estimates of the impact of climate change may be downward biased relative to the preferred long-run effect that allows for all economic substitutions. If the degree of climate change is "small," however, our estimates are equal to the preferred long-run effect. One final note is that in response to year-to-year fluctuations, farmers are able to adjust their mix of inputs (e.g., fertilizer and irrigated water usage), so the subsequent estimates are preferable to production function estimates that don't allow for any adaptation.

\section{Data Sources and Summary Statistics}

To implement the analysis, we collected the most detailed and comprehensive data available on agricultural production, temperature, precipitation, and soil quality. This section describes these data and reports some summary statistics.

\section{A. Data Sources}

Agricultural Production. The data on agricultural production come from the 1978, 1982, 1987, 1992, 1997, and 2002 Censuses of Agriculture. The Census has been conducted roughly every 5 years since 1925. The operators of all farms and ranches from which $\$ 1,000$ or more of agricultural products are produced and sold, or normally would have been sold, during the census year, are required to respond to the census forms. For confidentiality reasons, counties are the finest geographic unit of observation in these data.

In much of the subsequent regression analysis, county-level agricultural profits per acre of farmland is the dependent variable. This numerator of this variable is constructed as the difference between the market value of agricultural products sold and total production expenses across all farms in a county. The production expense information was not collected in 1978 or 1982, so the 1987, 1992, 1997, and 2002 data are the basis for the analysis. The denominator includes acres devoted to crops, pasture, and grazing.

The revenues component measures the gross market value before taxes of all agricultural products sold or removed from the farm, regardless of who received the payment. Importantly, it does not

coverage. Moreover, the state by year fixed effects provide a more flexible way to control for state-level variation in price, because they control for all unobserved factors that vary at the state by year level. 
include income from participation in federal farm programs ${ }^{8}$, labor earnings off the farm (e.g., income from harvesting a different field), or nonfarm sources. Thus, it is a measure of the revenue produced with the land.

Total production expenses are the measure of costs. It includes expenditures by landowners, contractors, and partners in the operation of the farm business. Importantly, it covers all variable costs (e.g., seeds, labor, and agricultural chemicals/fertilizers). It also includes measures of interest paid on debts and the amount spent on repair and maintenance of buildings, motor vehicles, and farm equipment used for farm business. Its chief limitation is that it does not account for the rental rate of the portion of the capital stock that is not secured by a loan so it is only a partial measure of farms' cost of capital. Just as with the revenue variable, the measure of expenses is limited to those that are incurred in the operation of the farm so, for example, any expenses associated with contract work for other farms is excluded. ${ }^{9}$

We utilize the variable on the value of land and buildings as the dependent variable in our replication of the hedonic approach. This variable is available in all six Censuses. Finally, we use the Census data to examine the relationship between the three most important crops (i.e., corn for grain, soybean, and wheat for grain) yields and annual weather fluctuations. Crop yields are measured as total bushels of production per acres planted.

Soil Quality Data. No study of agricultural land values would be complete without data on soil quality and we rely on the National Resource Inventory (NRI) for our measures of these variables. The NRI is a massive survey of soil samples and land characteristics from roughly 800,000 sites that is conducted in Census years. We follow the convention in the literature and use the measures of susceptibility to floods, soil erosion (K-Factor), slope length, sand content, clay content, irrigation, and permeability as determinants of land prices and agricultural profits. We create county-level measures by taking weighted averages from the sites that are used for agriculture, where the weight is the amount of land the sample represents in the county. Since the composition of the land devoted to agriculture varies within counties across Censuses, we use these variables as covariates. Although these data provide a rich portrait of soil quality, we suspect that they are not comprehensive. It is this possibility of omitted measures of soil quality and other determinants of profits that motivate our approach.

Climate and Weather Data. The climate data are derived from the Parameter-elevation

\footnotetext{
${ }^{8}$ An exception is that it includes receipts from placing commodities in the Commodity Credit Corporation (CCC) loan program. These receipts differ from other federal payments because farmers receive them in exchange for products.

${ }^{9}$ The Censuses contain separate variables for subcategories of revenue (e.g., revenues due to crops and dairy sales), but expenditures are not reported separately for these different types of operations. Consequently, we cannot provide separate measures of profits by these categories and instead focus on total agriculture profits.
} 
Regressions on Independent Slopes Model (PRISM). ${ }^{10}$ This model generates estimates of precipitation and temperature at $4 \times 4$ kilometers grid cells for the entire US. The data that are used to derive these estimates are from the more than 20,000 weather stations in the National Climatic Data Center's Summary of the Month Cooperative Files. The PRISM model is used by NASA, the Weather Channel, and almost all other professional weather services. It is regarded as one of the most reliable interpolation procedures for climatic data on a small scale.

This model and data are used to develop month by year measures of precipitation and temperature for the agricultural land in each county for the $1970-2000$ period. This was accomplished by overlaying a map of land uses on the PRISM predictions for each grid cell and then by taking the simple average across all agricultural land grid cells. ${ }^{11}$ To replicate the previous literature's application of the hedonic approach, we calculated the climate normals as the simple average of each county's annual monthly temperature and precipitation estimates between 1970 and two years before the relevant Census year. Furthermore, we follow the convention in the literature and include the January, April, July, and October estimates in our specifications so there is a single measure of weather from each season.

Although the monthly averages may be appropriate for a hedonic analysis of property values, there are better methods for modeling the effect of weather on annual agricultural profits. Agronomists have shown that plant growth depends on the cumulative exposure to heat and precipitation during the growing season. The standard agronomic approach for modeling temperature is to convert daily temperatures into degree days, which represent heating units (Hodges 1991; Grierson 2002). The effect of heat accumulation is nonlinear as temperature must be above a threshold for plants to absorb heat and below a ceiling, as plants cannot absorb extra heat when temperature is too high. Additionally, temperatures above some point become harmful. These thresholds or bases vary across crops, but we join SHF (2005b) and follow Ritchie and NeSmith's (1991) suggested characterization for the entire agricultural sector and use a base of $46.4^{\circ}$ Fahrenheit (F) and a ceiling of $89.6^{\circ} \mathrm{F}$ (or $8^{\circ}$ and $32^{\circ} \mathrm{C}$ ). Ritchie and NeSmith also discuss the possibility of a temperature threshold at $93.2^{\circ} \mathrm{F}\left(34^{\circ} \mathrm{C}\right)$, beyond which increases in temperature are harmful. However, we ignore this possibility since there is not enough support in our data to identify its effect. ${ }^{12}$

We use daily-level data on temperatures and calculate growing season degree days between April $1^{\text {st }}$ and September $30^{\text {th }}$, which covers the growing season for most crops, except winter wheat (U.S. Department of Agriculture, NASS 1997). The degree days variable is calculated so that a day with a

\footnotetext{
${ }^{10}$ PRISM was developed by the Spatial Climate Analysis Service at Oregon State University for the National Oceanic and Atmospheric Administration. See http://www.ocs.orst.edu/prism/docs/przfact.html for further details.

${ }^{11} \mathrm{We}$ are indebted to Shawn Bucholtz at the USDA for generously generating this weather data.

12 Over our sample period, the average county in the United States faced 0.2 growing season degree days of such harmful temperature.
} 
mean temperature: below $46.4^{\circ} \mathrm{F}$ contributes 0 degree days; between $46.4^{\circ} \mathrm{F}$ and $89.6^{\circ} \mathrm{F}$ contributes the number of degrees $\mathrm{F}$ above 46.4 degree days; above $89.6^{\circ} \mathrm{F}$ contributes 43.2 degree days. The growing season degree day variable is then calculated by summing the daily measures over the entire growing season.

Unfortunately, the monthly PRISM data do not provide information on measures of actual growing season degree days. To measure these degree day variables, we used daily-level data on mean daily temperature from the approximately 8,000 operational weather stations located in the U.S. during our sample period. These data were obtained from the National Climatic Data Center "Cooperative Summary of the Day" Files. The construction of the sample used is described with more details in the appendix. Our use of daily data to calculate degree days is an important improvement over previous work that has estimated growing season degree days with monthly data and distributional assumptions (SHF $2005 b) .^{13}$

In the specifications that use the degree days measures of temperature, the measure of precipitation is total precipitation in the growing season. This measure is just the sum of precipitation across the growing season months in the relevant year calculated from the PRISM data.

Climate Change Predictions. We rely on two sets of predictions about climate change to develop our estimates of its effects on US agricultural land. The first predictions follow the convention in the literature and rely on the climate change scenario from the $1^{\text {st }}$ IPCC report associated with a doubling of atmospheric concentrations of greenhouse gases by the end of the $21^{\text {st }}$ century. (IPCC 1990; NAS 1992) This model assumes a uniform (across months and regions of the US and their interaction) $5^{\circ} \mathrm{F}$ increase in temperature and $8 \%$ increase in precipitation. The convention in the previous literature is to use these predictions. $^{14}$

The second set of predictions is from the Hadley Centre's $2^{\text {nd }}$ Coupled Ocean-Atmosphere General Circulation Model, which we refer to as Hadley 2 (T. C. Johns et al. 1997). This model of climate is comprised of several individually modeled components -- the atmosphere, the ocean, and sea ice -- which are equilibrated using a "spinup" process. This model was used in the $2^{\text {nd }}$ IPCC report (Houghton 1996). To obtain predicted impacts on temperature and precipitation, we assume a $1 \%$ per year compounded increase in both carbon dioxide and IS92A sulphate aerosols, which implies that greenhouse gas concentrations will increase to roughly 2.5 times their current levels by the end of the $21 \mathrm{st}$ century. These assumptions about emissions and resulting climate change predictions are standard assumptions and result in middle of the range predictions. The Hadley 2 model and this emission

\footnotetext{
${ }^{13}$ See Thom (1966) who outlines a method to recover degree days from monthly data by making a normality assumption.

${ }^{14}$ Mendelsohn, Nordhaus, and Shaw (1994 and 1999) and SHF (2005a) also calculate the effect of global climate change based on these estimated changes in temperature and precipitation.
} 
scenario are used to obtain monthly state-level predictions for January 1994 through December 2099 (see the Data Appendix for further details). ${ }^{15}$ We focus on the "medium term" and "long run" effects on climate, which are defined as the temperature and precipitation averages across the 2020-2049 and 20702099 predictions, respectively.

\section{B. Summary Statistics}

Agricultural Finances, Soil, and Weather Statistics. Table 1 reports county-level summary statistics from the three data sources for 1978, 1982, 1987, 1992, 1997, and 2002. The sample is comprised of a balanced panel of 2,268 counties. ${ }^{16}$ Over the period, the number of farms per county varied between 680 and 800 . The total number of acres devoted to farming declined by roughly $7.5 \%$. At the same time, the acreage devoted to cropland was roughly constant implying that the decline was due to reduced land for livestock, dairy, and poultry farming. The mean average value of land and buildings per acre in the Census years ranged between $\$ 892$ and \$1,370 (1997\$) in this period, with the peak and trough occurring in 1978 and 1992, respectively. ${ }^{17}$

The second panel details annual financial information about farms. We focus on 1987-2002, since complete data is only available for these four censuses. During this period the mean county-level sales of agricultural products ranged from $\$ 72$ to $\$ 80$ million. Although it is not reported here, the share of revenue from crop products increased from $43.7 \%$ to $47.9 \%$ in this period with the remainder coming from the sale of livestock and poultry. Farm production expenses grew from $\$ 57$ million to $\$ 65$ million. The mean county profits from farming operations were \$14.4 million, \$14.0 million, \$18.6 million, \$10.0 million or $\$ 42, \$ 41, \$ 56$ and $\$ 30$ per acre in 1987, 1992, 1997, and 2002 respectively. These profit figures do not include government payments, which are listed at the bottom of this panel. The subsequent analysis of profits also excludes government payments.

The third panel lists the means of the available measures of soil quality, which are key determinants of lands' productivity in agriculture. These variables are essentially unchanged across years since soil and land types at a given site are generally time-invariant. The small time-series variation in

${ }^{15}$ The Hadley Centre has released a $3^{\text {rd }}$ climate model, which has some technical improvements over the $2^{\text {nd }}$ one. We do not use it for this paper's predictions, because it has not yet been run on a monthly time by subnational scale over the course of the entire $21^{\text {st }}$ century. Thus, we would not be able to make the state-level predictions about climate that are possible with the $2^{\text {nd }}$ model.

${ }^{16}$ Observations from Alaska and Hawaii were excluded. We also dropped all observations from counties that had missing values for one or more years on any of the soil variables, acres of farmland, acres of irrigated farmland, per capita income, population density, and latitude at the county centroid. The sample restrictions were imposed to provide a balanced panel of counties from 1978-2002 for the subsequent regressions where these variables are important controls.

17 All dollar values are in 2002 constant dollars. All entries are simple averages over the 2,268 counties, with the exception of "Average Value of Land/Bldg (1\$/acre)" and "Profit Per Acre (1\$/acre)", which are weighted by acres of farmland. 
these variables is due to changes in the composition of land that is used for farming. Notably, the only measure of salinity is from 1982, so we use this measure for all years.

The final panel reports on annual weather. The precipitation variables are measured in inches. The monthly mean temperature and degree day variables are reported in Fahrenheit degrees. On average, July is the wettest month and October is the driest. The average precipitation in these months in the five census years is 3.9 inches and 2.0 inches, respectively. It is evident that there is less year-to-year variation in the national mean of temperature than precipitation. The growing season degree days and total precipitation range from roughly 2,600 to 3,100 degree days and 19.3 to 21.6 inches, respectively.

Figures $2 \mathrm{~A}$ and $2 \mathrm{~B}$ provide an opportunity to examine the variability in growing season degree days and precipitation (calculated as the mean between 1970 and 2000) at the county level across the country. In Figure 2 A (B), counties in the highest quartile for growing season degree days (precipitation) are colored dark gray, counties between the $25^{\text {th }}$ and $75^{\text {th }}$ percentile are dashed light grey, and counties in the lowest quartile are light grey. The dividing lines for these categories are $>4375$ degree days $(25.5$ inches), and $<2464$ degree days ( $<18.0$ inches). The "inter-quartile" category consists of counties falling between the thresholds. The degree day figure reveals that the Southern part of the US is the warmest, although there is a lot of variability even within states. The precipitation figure shows that the lowest quartile of precipitation is virtually all located to the west of the 100 degree meridian. This line loosely separates land where farming requires irrigation from areas where rainfall is sufficient to successfully grow crops.

Figure 2C depicts the average profit per acre at the county-level across the 1987-2002 Censuses of Agriculture. Here the three groupings are denoted by $>\$ 79.4$, between $\$ 12.0$ and $\$ 79.4$, and $<\$ 12.0$. It is evident from visual inspection that temperature and precipitation are not the only determinants of agricultural profits. The most profitable agricultural land is interspersed throughout the country but is especially concentrated in California (which benefits from heavy irrigation), the Eastern seaboard, the grain and corn growing regions in Illinois and Iowa, and North Carolina where tobacco farming is an important activity.

Climate Change Statistics. Table 2 reports on the predictions of some of the climate change models. All entries are calculated as the weighted average across the fixed sample of 2,268 counties, where the weight is the number of acres of farmland. Under the "Actual" column we show the 1970-2000 averages of each of the listed variables. The top panel reports on the benchmark global warming model from the $1^{\text {st }}$ IPCC report, which predicts uniform (across season and space) increases of $5^{\circ} \mathrm{F}$ and $8 \%$ in precipitation. The panel reports the actual and predicted mean temperatures and precipitation (as well as their difference) for January, April, July, and October. The table also contains entries for growing season degree days and total precipitation. All of the information is provided separately for non-irrigated (i.e., 
dryland) and irrigated counties. We define a county as irrigated if at least $10 \%$ of its farmland is irrigated and this definition is used throughout the remainder of the paper.

The bottom panel reports on the medium and long run predicted effects from the Hadley 2 Global Warming model for growing season degree days and precipitation. This information is listed for the country as a whole and for each of the four Census Bureau's regions.

The model predicts a mean increase in degree days of roughly 800 in the medium term and approximately twice that by the end of the century (i.e., the long run). The most striking regional difference is the dramatic increase in temperature in the South. Its long run predicted increase in degree days of roughly 2,700 among non-irrigated counties greatly exceeds the approximate increases of 1,700, 800 , and 1,400 in the Northeast, Midwest, and West, respectively. The overall average increase in growing season precipitation in the long run is approximately 2.5 inches, with the largest increases occurring in the Northeast and South.

Figures 3A and 3B report on the Hadley 2 Model's predicted changes in growing season degree days and total precipitation in the long run at the state-level. ${ }^{18}$ In Figure $3 \mathrm{~A}$, it is notable that even within regions there is variability in the increase in degree days. For example, California is predicted to have an increase of 2590 degree days but Arizona's predicted change is only 1450. Further Pennsylvania's increase (2951) is substantially larger than its neighbors. There is even greater intra-region variability in the increase in growing season precipitation. The important inter- and intra-regional variation in the changes in temperature and precipitation are an under-recognized feature of the predicted changes in climate. These state-level predicted changes are used in the remainder of the paper to infer the economic impacts of climate change.

Weather Variation Statistics. In our preferred approach, we aim to infer the effects of weather fluctuations on agricultural profits. We focus on regression models that include county and year fixed effects and county and state by year fixed effects. It would be ideal if after adjustment for these fixed effects, the variation in the weather variables that remains is as large as those predicted by the climate change models used in this study. In this case, our predicted economic impacts will be identified from the data, rather than by extrapolation due to functional form assumptions. Recall, the average predicted increase in growing season degree days in Table 2 ranges from about 700 (benchmark model) to 1,600 (long-run Hadley 2 model). The average predicted increase in growing season precipitation ranges from 0.6 to 2.7 inches.

Panel A of Table 3 reports on the magnitude of the deviations between counties' yearly weather

\footnotetext{
${ }^{18}$ In Figure 3A (B), counties in the highest quartile for growing season degree days (precipitation) are colored dark gray, counties between the $25^{\text {th }}$ and $75^{\text {th }}$ percentile are dashed light grey, and counties in the lowest quartile are light grey. The dividing lines for these categories are $>2013$ degree days (4.9 inches), between 833 and 2013 degree days ( 0.8 and 4.9 inches), and $<833$ degree days $(<0.8$ inches).
} 
realizations and their long run averages after subtracting the deviation between the national average weather realization and the national long run average. Therefore, it provide an opportunity to assess the magnitude of the variation in growing season degree days and precipitation after adjustment for permanent county factors (e.g., whether the county is usually hot or wet) and national time varying factors (e.g., whether it was a hot or wet year). Specifically, the entries report the fraction of counties with deviations at least as large as the one reported in the column heading. For example, consider the 2002 degree days row, it indicates that $57 \%, 19 \%$, and $2 \%$ of counties had deviations larger than 200,800 , and 1,400 degree days, respectively. Panel B repeats this exercise after subtracting the deviation between a states' yearly weather realization and the states' long run average (rather than the national deviation). These entries report on the variation in weather that remains after the inclusion of county and state by year fixed effects in the subsequent specifications.

Temperature and precipitation deviations of the magnitudes predicted by the climate change models occur in the data in both panels. This is especially true of precipitation where in Panel A nearly $31-35 \%$ (24-28\% in Panel B) of counties have a deviation larger than 2.5 inches, which roughly corresponds to the average predicted long-run increase in the long run Hadley 2 model. In the case of temperature, roughly $9-11 \%$ of counties have deviations at least as great as the benchmark 800 degree days. The long-run Hadley 2 model predicts increases of 1,600 degree days. This increase is nonparametrically identified, although it would come from a relatively small subset of the data. However, 4$5 \%$ of counties have deviations as large as 1000 degree days in a year (even in Panel B). Finally, it is noteworthy that differencing out state weather shocks does not substantially reduce the frequency of large deviations, highlighting that there are important regional patterns to weather shocks.

\section{Econometric Strategy}

\section{A. The Hedonic Approach}

This section describes the econometric framework that we use to assess the consequences of global climate change. We initially consider the hedonic cross sectional model that has been predominant in the previous literature (MNS 1994, 1999; SHF 2005a, b). Equation (3) provides a standard formulation of this model:

$$
\mathrm{y}_{\mathrm{ct}}=\mathrm{X}_{\mathrm{ct}}{ }^{\prime} \beta+\Sigma_{\mathrm{i}} \theta_{\mathrm{i}} \mathrm{f}_{\mathrm{i}}\left(\overline{\mathrm{W}}_{\mathrm{ic}}\right)+\varepsilon_{\mathrm{ct}}, \quad \quad \varepsilon_{\mathrm{ct}}=\alpha_{\mathrm{c}}+\mathrm{u}_{\mathrm{ct}},
$$

where $y_{c t}$ is the value of agricultural land per acre in county $\mathrm{c}$ in year $\mathrm{t}$. The $\mathrm{t}$ subscript indicates that this model could be estimated in any year for which data is available.

$\mathrm{X}_{\mathrm{ct}}$ is a vector of observable determinants of farmland values. A $\mathrm{t}$ subscript is included on the $\mathrm{X}$ 
vector, because it includes some time-varying factors that affect land values. $\overline{\mathrm{W}}_{\text {ic }}$ represents a series of climate variables for county c. We follow MNS and let $\mathrm{i}$ indicate one of eight climatic variables. In particular, there are separate measures of temperature and total precipitation in January, April, July, and October so there is one month from each quarter of the year. Moreover, as emphasized by SHF (2005a), it is important to allow the effect of climate to differ across dryland and irrigated counties. Accordingly, we estimate equation (3) by including interactions of all the climate variables and indicators for dryland and irrigated counties.

The appropriate functional form for each of the climate variables is unknown, but in our replication of the hedonic approach we follow the convention in the literature and model the climatic variables with linear and quadratic terms, separately by irrigation status. The last term in equation (3) is the stochastic error term, $\varepsilon_{\mathrm{ct}}$, that is comprised of a permanent, county-specific component, $\alpha_{\mathrm{c}}$, and an idiosyncratic shock, $\mathrm{u}_{\mathrm{ct}}$.

The coefficient vector $\theta$ is the 'true' effect of climate on farmland values and its estimates are used to calculate the overall effect of climate change associated with the benchmark 5-degree Fahrenheit increase in temperature and eight percent increase in precipitation. Since the total effect of climate change is a linear function of the components of the $\theta$ vector, it is straightforward to formulate and implement tests of the effects of alternative climate change scenarios on agricultural land values. ${ }^{19} \mathrm{We}$ will report the standard errors associated with the overall estimate of the effect of climate change. However, the total effect of climate change is a function of 32 parameter estimates when the climate variables are modeled with a quadratic, so it is not surprising that statistical significance is elusive. This issue of sampling variability has generally been ignored in the previous literature. ${ }^{20}$

Consistent estimation of the vector $\theta$, and consequently of the effect of climate change, requires that $\mathrm{E}\left[\mathrm{f}_{\mathrm{i}}\left(\overline{\mathrm{W}}_{\mathrm{ic}}\right) \varepsilon_{\mathrm{ct}} \mid \mathrm{X}_{\mathrm{ct}}\right]=0$ for each climate variable $\mathrm{i}$. This assumption will be invalid if there are unmeasured permanent $\left(\alpha_{c}\right)$ and/or transitory $\left(\mathrm{u}_{\mathrm{ct}}\right)$ factors that covary with the climate variables. To obtain reliable estimates of $\theta$, we collected a wide range of potential explanatory variables including all the soil quality variables listed in Table 1 , as well as per capita income and population density. ${ }^{21}$ We also estimate specifications that include state fixed effects.

\footnotetext{
${ }^{19}$ Since we use a quadratic model for the climate variables, each county's predicted impact is calculated as the discrete difference in agricultural land values at the county's predicted temperatures and precipitation after climate change and its current climate (i.e., the average over the 1970-2000 period).

${ }^{20}$ SHF (2005a) is a notable exception.

${ }^{21}$ Previous research suggests that urbanicity, population density, the local price of irrigation, and air pollution concentrations are important determinants of land values (Cline 1996; Plantinga, Lubowski, and Stavins 2002; SHF 2005a, b; Chay and Greenstone 2005). Comprehensive data on the price of irrigation and air pollution concentrations were unavailable.
} 
There are three further issues about equation (3) that bear noting. First, it is likely that the error terms are correlated among nearby geographical areas. For example, unobserved soil productivity is likely to be spatially correlated. In this case, the standard OLS formulas for inference are incorrect since the error variance is not spherical. In absence of knowledge on the sources and the extent of residual spatial dependence in land value data, we adjust the standard errors for spatial dependence of an unknown form following the approach of Conley (1999). The basic idea is that the spatial dependence between two observations will decline as the distance between the counties increases. ${ }^{22}$ Throughout the paper, we present standard errors calculated with the Eicker-White formula that allows for heteroskedasticity of an unspecified nature. In addition we also present the Conley standard errors for our preferred fixed-effect models.

Second, it may be appropriate to weight equation (3). Since the dependent variable is countylevel farmland values per acre, we think there are two complementary reasons to weight by the square root of acres of farmland. First, the estimates of the value of farmland from counties with large agricultural operations will be more precise than the estimates from counties with small operations and this weight corrects for the heteroskedasticity associated with the differences in precision. Second with this weight, the weighted mean of the dependent variable is equal to the mean value of farmland per acre in the country.

MNS (1994, 1999) and SHF (2005a) both use the square root of the percent of the county in cropland and the square root of total revenue from crop sales as weights. We elected not to report the results based on these approaches in the main tables, since the motivation for these weighting schemes is less transparent. For example, it is difficult to justify the assumptions about the variance-covariance matrix that would motivate these weights as a solution to heteroskedasticity. Further, although these weights emphasize the counties that are most important to total agricultural production, they do so in an unconventional manner. Consequently, the weighted means of the dependent variable with these weights have a non-standard interpretation. For completeness, we report estimates from these weighting schemes in a footnote below but again keep them out of the tables

Third to probe the robustness of the hedonic approach, we estimate it with data from each of the Census years. If this model is specified correctly, the estimates will be unaffected by the year in which the model is estimated. If the estimates differ across years, this may be interpreted as evidence that the hedonic model is misspecified.

\footnotetext{
${ }^{22}$ More precisely, the Conley (1999) covariance matrix estimator is obtained by taking a weighted average of spatial autocovariances. The weights are given by the product of Bartlett kernels in two dimensions (north/south and east/west), which decline linearly from 1 to 0 . The weights reach 0 when one of the coordinates exceeds a prespecified cutoff point. Throughout we choose the cutoff points to be 7 degrees of latitude and longitude, corresponding to distances of about 500 miles.
} 


\section{B. A New Approach}

One of this paper's primary points is that the cross-sectional hedonic equation is likely to be misspecified. As a possible solution to these problems, we fit:

$$
\mathrm{y}_{\mathrm{ct}}=\alpha_{\mathrm{c}}+\gamma_{\mathrm{t}}+\mathrm{X}_{\mathrm{ct}}{ }^{\prime} \beta+\Sigma_{\mathrm{i}} \theta_{\mathrm{i}} \mathrm{f}_{\mathrm{i}}\left(\mathrm{W}_{\mathrm{ict}}\right)+\mathrm{u}_{\mathrm{ct}} .
$$

There are a number of important differences between equations (4) and (3). For starters, the equation includes a full set of county fixed effects, $\alpha_{c}$. The appeal of including the county fixed effects is that they absorb all unobserved county-specific time invariant determinants of the dependent variable. ${ }^{23}$ The equation also includes year indicators, $\gamma_{t}$, that control for annual differences in the dependent variable that are common across counties. Our preferred specification replaces the year fixed effects with state by year fixed effects $\left(\gamma_{\mathrm{st}}\right)$.

The inclusion of the county fixed effects necessitates two substantive differences in equation (4), relative to (3). First, the dependent variable, $y_{c t}$, is now county-level agricultural profits, instead of land values. This is because land values capitalize long run characteristics of sites and, conditional on county fixed effects, annual realizations of weather should not affect land values. However, weather does affect farm revenues and expenditures and their difference is equal to profits. The association between the weather variables and agricultural profits may be due to changes in revenues or operating expenditures and we also show separate results for these two determinants of profits.

Second, since there is no temporal variation in $\overline{\mathrm{W}}_{\mathrm{ic}}$, it is impossible to estimate the effect of the long run climate averages in a model with county fixed-effects. Consequently, we replace the climate variables with annual realizations of weather, $\mathrm{W}_{\text {ict }}$. As explained before, we follow the standard agronomic approach and model temperature by using growing season degree days, defined with a base of $46.4^{\circ} \mathrm{F}$ and a ceiling of $89.6^{\circ} \mathrm{F}$. Similarly, we model the effect of precipitation on agricultural profits per acre by using growing season precipitation. Once again, we let the effect of these variables on profits per acre to differ across irrigated and dryland counties. We allow for a quadratic in each of these variables.

The validity of any estimate of the impact of climate change based on equation (4) rests crucially on the assumption that its estimation will produce unbiased estimates of the $\theta$ vector. Formally, the consistency of each $\theta_{\mathrm{i}}$ requires $\mathrm{E}\left[\mathrm{f}_{\mathrm{i}}\left(\mathrm{W}_{\mathrm{ict}}\right) \mathrm{u}_{\mathrm{ct}} \mid \mathrm{X}_{\mathrm{ct}}, \alpha_{\mathrm{c}}, \gamma_{\mathrm{st}}\right]=0$. By conditioning on the county and state by year fixed effects, the $\theta_{i}$ 's are identified from county-specific deviations in weather about the county averages after controlling for shocks common to all counties in a state. This variation is presumed to be orthogonal to unobserved determinants of agricultural profits, so it provides a potential solution to the

\footnotetext{
${ }^{23}$ Interestingly, the fixed effects model was first developed by Hoch (1958 and 1962) and Mundlak (1961) to account for unobserved heterogeneity in estimating farm production functions.
} 
omitted variables bias problems that appear to plague the estimation of equation (3). A shortcoming of this approach is that all the fixed effects are likely to magnify the importance of misspecification due to measurement error, which generally attenuates the estimated parameters.

\section{Results}

This section is divided into three subsections. The first provides some suggestive evidence on the validity of the hedonic approach and then present results from that approach. The second subsection presents results from the fitting of equation (4) to estimate the impact of climate change on the US agricultural sector. It also probes the distributional consequences of climate change across the country. The third and final subsection estimates the effect of climate change on crop yields for the three most important crops (i.e., corn for grain, soybeans, and wheat for grain). The intent is to determine the source of the profit results.

\section{A. Estimates of the Impact of Climate Changes from the Hedonic Approach}

As the previous section highlighted, the hedonic approach relies on the assumption that the climate variables are orthogonal to the unobserved determinants of land values. We begin by examining whether these variables are orthogonal to observable predictors of farm values. While this is not a formal test of the identifying assumption, there are at least two reasons that it may seem reasonable to presume that this approach will produce valid estimates of the effects of climate when the observables are balanced. First, consistent inference will not depend on functional form assumptions (e.g., linear regression adjustment when the conditional expectations function is nonlinear) on the relations between the observable confounders and farm values. Second, the unobservables may be more likely to be balanced (Altonji, Elder, and Taber 2000).

Table 4A shows the association of the temperature variables with farm values and likely determinants of farm values and $4 \mathrm{~B}$ does the same for the precipitation variables. To understand the structure of the tables, consider the upper-left corner of Table 4A. The entries in the first four columns are the means of county-level farmland values, soil characteristics, and socioeconomic and locational attributes by quartile of the January temperature normal. Here, normal refers to the county average temperature over the period 1970-2000. The means are calculated with data from the six Censuses but are adjusted for year effects. Throughout Tables 4A and 4B, quartile 1 (4) refers to counties with a climate normal in the lowest (highest) quartile, so, for example, quartile 1 counties for January temperature are the coldest.

The fifth column reports the F-statistic from a test that the means are equal across the quartiles. 
Since there are six observations per county, the test statistics allows for county-specific random effects. A value of 2.37 (3.34) indicates that the null hypothesis can be rejected at the 5\% (1\%) level. If climate were randomly assigned across counties, there would be very few significant differences.

It is immediately evident that the observable determinants of farmland values are not balanced across the quartiles of weather normals. In 112 of the 112 cases, the null hypothesis of equality of the sample means of the explanatory variables across quartiles can be rejected at the $1 \%$ level. ${ }^{24}$ In many cases the differences in the means are large, implying that rejection of the null is not simply due to the sample sizes. For example, the fraction of the land that is irrigated and the population density (a measure of urbanicity) in the county are known to be important determinants of the agricultural land values and their means vary dramatically across quartiles of the climate variables. Overall, the entries suggest that the conventional cross-sectional hedonic approach may be biased due to incorrect specification of the functional form of the observed variables and potentially due to unobserved variables.

With these results in mind, Table 5 reports on the implementation of the hedonic approach outlined in equation (3). Every specification allows for a quadratic in each of the 8 climate variables and, as recommended by SHF (2005a), their effects are allowed to vary in irrigated and dryland counties. We also allow for intercept differences across irrigated and dryland counties. All other parameters are constrained to be equal across these two sets of counties.

The entries report the predicted changes in land values in billions of 2002 dollars (and their standard errors in parentheses) from the benchmark increases of 5 degrees Fahrenheit in temperatures and $8 \%$ in precipitation. These predicted changes are based on the estimated climate parameters from the fitting of equation (3). The 56 different sets of estimates of the national impact on land values are the result of 7 different data samples, 4 specifications, and 2 assumptions about the correct weights. The data samples are denoted in the row headings. There is a separate sample for each of the Census years and the seventh is the result of pooling data from the six Censuses.

The A, B, C, and D pairs of columns correspond to four sets of control variables. In the A columns, the climate parameters are the only regressors so the resulting predictions are not adjusted for any other observable determinants of farmland values. The entries in the B columns specification are adjusted for the soil characteristics in Table 1, as well as per capita income and population density and their squares. The $\mathrm{C}$ columns specification adds state fixed effects to account for all unobserved differences across states (e.g., soil quality and state agricultural programs). In the specification in the D columns latitude (measured at the county centroid) is an additional covariate. We believe that it is

\footnotetext{
${ }^{24} \mathrm{We}$ also divided the sample into dryland and irrigated counties, where a county is defined as irrigated if at least $10 \%$ of the farmland is irrigated and the other counties are labeled dryland. Among the dryland (irrigated) counties, the null hypothesis of equality of the sample means of the explanatory variables across quartiles can be rejected at the $1 \%$ level for 111 (96) of the 112 covariates.
} 
inappropriate to control for latitude because it confounds temperature, so our preferred specification is the one in the C columns. ${ }^{25}$ However, the previous literature has generally controlled for latitude so the column D results are presented for completeness. ${ }^{26}$ The exact controls are summarized in the rows at the bottom of the table and detailed in the Data Appendix.

Among the A, B, C, and D pairs of columns, the column "[0]" regression equations are unweighted. The column "[1]" entries are the result of weighting by the square root of acres of farmland. We re-emphasize that this seems like the most sensible assumption about the weights, because it corrects for the heteroskedasticity associated with the differences in precision in the dependent variable across counties.

The predicted change in land values per acre is calculated separately for each county as the difference in predicted land values with the current climate and the climate predicted by the benchmark model. ${ }^{27}$ We then sum each county's change in per acre land values multiplied by the number of acres devoted to agriculture in that county across the 2,124 counties in the sample to calculate the national effect. $^{28}$ For the year-specific estimates, the heteroskedastic-consistent standard errors (White 1980) associated with each estimate are reported in parentheses. ${ }^{29}$ For the pooled estimates, the standard errors reported in parentheses allow for clustering at the county level.

We initially focus on the year-specific estimates in the top panel. The most striking feature of the entries is the tremendous variation in the estimated impact of climate change on agricultural land values. For example in the preferred $\mathrm{B}$ and $\mathrm{C}$ columns, the estimates range between $+\$ 320$ billion and $-\$ 200$ billion, which are $38 \%$ and $-24 \%$ of the total value of land and structures in this period, respectively. Figure 4 graphically captures the variability of these 48 estimates by plotting each of the point estimates,

\footnotetext{
${ }^{25}$ Our view is that latitude should not be included as a covariate because it so highly correlated with temperature. For instance, Table 4A demonstrates that the F-statistics associated with the test of equality of the means of latitude across the temperature normals are roughly an order of magnitude larger than the next largest F-statistics. This suggests that latitude captures some of the variation that should be assigned to the temperature variables and thereby leads to misleading predictions about the impact of climate change.

${ }^{26}$ This specification is identical to MNS' (1994) preferred specification, except that it includes state fixed effects and does not include elevation. It is also very similar to SHF's (2005b) preferred specification, which only has a subset of our soil variables (although it includes state fixed effects and like the present analysis excludes elevation). Interestingly, the addition of elevation to the pooled D [1] specification causes the standard error to increase by more than six-fold, which means that the point estimates have little empirical content. We conclude that this is evidence that elevation is collinear with the climate variables and that it is appropriate to leave this variable out of the estimating equation.

${ }^{27}$ Due to the nonlinear functional form assumptions about the climate variables, we calculate this discrete difference in land values rather than simply multiplying the marginal impact of each of the climate variables by the magnitude of the change. Of course, we use the climate parameters from the irrigated (dryland) counties when calculating the effect for the irrigated (dryland) counties.

${ }^{28}$ For the analysis in Tables 4 and 5, we add the sample selection rule that the variable for the value of land and buildings is non-missing in all census years to the rules used in Table 1. The result is that the balanced sample has 144 fewer counties.
} 
along with their $+/-1$ standard error range. The wide variability of the estimates is evident visually and underscores the sensitivity of this approach to alternative assumptions and data sources.

An especially unsettling feature of these results is that even when the covariates and weighting assumption are held constant, the estimated impact can vary greatly depending on the sample. For example, the $\mathrm{C}[0]$ regression produces an estimated impact of roughly $+\$ 320$ billion in 1978 but essentially $\$ 0$ in 2002. This difference is large, even in the context of the sampling errors.

We also test for the equality of the marginal effects of each climate variables across the six census years. Using the estimates from the preferred C [1] model, we perform these tests separately for irrigated and dryland counties. The equality of the 8 marginal effects across years is rejected at the 5\% level in all 8 cases for dryland counties. For irrigated counties, the null of equality is rejected in 5 out of 8 cases. Overall, these results are troubling because there is no ex-ante reason to believe that the estimates from a particular year are more reliable than those from other years.

The second panel reports the pooled results, which provide an appealing method to summarize the estimates from each of the 8 combinations of specifications and weighting procedures. ${ }^{30}$ The estimated change in property values from the benchmark global warming scenario ranges from $-\$ 68$ billion (with a standard error of $\$ 38$ billion) to $+\$ 115$ billion (with a standard error of $\$ 52$ billion). The preferred column $\mathrm{C}$ specifications indicate increases of $\$ 87$ and $\$ 102$ billion and these estimates are statistically significant at the $10 \%$ and $1 \%$ levels, respectively. ${ }^{31}$

The separate entries for non-irrigated (i.e., dryland) and irrigated counties indicate that across the specifications the predicted effects of climate change are concentrated in the dryland counties. It is interesting that in the preferred C [1] specification both dryland and irrigated counties are predicted to have statistically significant increases in land values. There are statistically significant positive and negative estimates for the dryland counties, which indicates that even within this subsample the estimates are sensitive to choices about the proper set of covariates and the weighting scheme. ${ }^{32}$

Overall, this subsection has produced a few important findings. First, the observable determinants of land prices are poorly balanced across quartiles of the climate normals. Second, the more

\footnotetext{
${ }^{29}$ Once we adjust for covariates (e.g., in panels B, C, and D), the Conley spatial standard errors are 20-30\% smaller than standard errors reported in Table 5.

${ }^{30}$ In the pooled regressions, the intercept and the parameters on all covariates, except the climate ones, are allowed to vary across years.

31 As discussed before, the previous literature has considered other weighting schemes. We replicated these estimates as well. Estimates from the cropland-weighted models range from $-\$ 428$ billion to $+\$ 304$ billion, while the estimates from the crop revenue-weighted models range from $-\$ 326$ billion to $+\$ 421$ billion. Thus, with these weights, the range of the estimates is even wider than with the weights used in Table 5.

${ }^{32}$ SHF (2005b) estimate a hedonic equation with data from dryland counties. They model climate with growing season degree days and precipitation and use a spatial weighting matrix. The results from this equation appear more stable. It is unclear whether this is due to the alternative modeling of climate, the weighting scheme, or both of these differences.
} 
reliable hedonic specifications suggest that on net climate change will be modestly beneficial for the US agriculture sector. Third, the hedonic approach produces estimates of the effect of climate change that are sensitive to seemingly small decisions about the specification, weighting procedure, and sample. Together, these findings suggest that the hedonic method may be unable to produce a credible estimate of the economic impact of climate change in the US. In light of the importance of the question, it is worthwhile to consider alternative methods. The remainder of the paper describes the results from one such alternative.

\section{B. Estimates of the Impact of Climate Change from Local Variation in Weather}

We now turn to our preferred approach that relies on annual fluctuations in weather to estimate the impact of climate change on agricultural profits. To provide intuition for the subsequent regression results, Figure 5A visually explores the relationship between profits per acre and growing season degree days using data the balanced sample of counties from the 1987-2002 Censuses. ${ }^{33}$ The figure plots the results from 4 separate regressions for county-level profits per acre, all of which are weighted by total county-level agricultural acres. The line "Year FE [Decile]" plots the parameter estimates on indicator variables for deciles of the distribution of growing season degree days at the midpoint of each decile's range. As the title of the line indicates, this regression also includes year fixed effects. The next two lines repeat this exercise but include year and county fixed effects and state by year and county fixed effects, respectively. The final line replaces degree day decile indicators with a quadratic in degree days and plots the conditional means at the midpoints of each decile's range. It is labeled "State by Year \& County FE [Quadratic].”

There are several important findings in this graph. First, in the "Year FE" line there is tremendous variation in profits per acre. Notably, it peaks in the $6^{\text {th }}$ decile (midpoint $=2,697$ degree days), which includes the overall mean of roughly 2,850 . Second, the addition of county fixed effects to the specification greatly reduces the variation in profits per acre. Further, the inclusion of state by year fixed effects further mitigates it. This finding is consistent with the hedonic results that temperature is confounded by many other factors and a failure to adjust for them will lead to severely biased estimates of its effect. Third, the modeling of degree days with a quadratic provides a good approximation to the less parametric approach. Fourth, and most importantly, the adjusted models show that even relatively large changes in degree days will have modest effects on profits per acre. This foreshadows the degree day results from the estimation of equation (4).

Figure 5B repeats this exercise for precipitation and leads to similar conclusions. It is evident

\footnotetext{
${ }^{33}$ For this figure and the remainder of the subsection, we add the sample selection rule that the variable for profits is non-missing in all census years to the rules used in Table 1. This yields a balanced sample of 2,262 counties.
} 
that precipitation is confounded by many other determinants of profits per acre and that county fixed effects greatly reduce this confounding. The primary difference is that profits per acre are increasing in growing season precipitation over the range of existing data.

Table 6A summarizes the results from the estimation of four versions of equation (4). The means of the dependent variable (i.e., county-level agriculture profits per acre) in dryland and irrigated counties are $\$ 31.27$ and $\$ 85.75$. Growing season degree days and precipitation are both modeled with a quadratic and allowed to differ in dryland and irrigated counties. Each specification includes a full set of county fixed effects as controls. In columns (1) and (2), the specification includes unrestricted year effects and these are replaced with state by year effects in columns (3) and (4). Additionally, the columns (2) and (4) specifications adjust for the full set of soil variables listed in Table 1, while the columns (1) and (3) estimating equations do not include these variables. All equations are weighted by the square root of total acres of farmland. The specification details are noted at the bottom of the table.

The table reports the marginal effects of the weather variables evaluated at the means for dryland and irrigated counties. Their heteroskedastic-consistent standard errors are in parentheses. The entries indicate that an increase of 1,000 degree days in dryland counties would lead to changes in per-acre profits ranging from $-\$ 1.90$ to $+\$ 1.60$. In irrigated counties the estimated impact varies from $-\$ 4.90$ to $\$ 2.60$, although these estimates are less precise than those from the dryland counties. The preferred specifications in columns (3) and (4) that include state by year fixed effects produce the point estimates at the high end of the ranges. Notably, the hypothesis that the marginal effects are equal in the two sets of counties cannot be rejected at the $1 \%$ level (although less strict criteria would lead to rejection).

The growing season precipitation results lead to similar conclusions. Specifically, the marginal effects suggest that a 1 inch increase in precipitation lead to a $-\$ 0.36$ to $\$ 0.17$ change in profits in dryland counties and a $\$ 0.66$ to $\$ 1.21$ increase in irrigated counties. ${ }^{34}$ The irrigated county estimates indicate that increased rainfall is more beneficial in these counties, which suggests that there are limited supplies of free irrigated water. Overall, these results confirm the visual impression from Figure 5 that suggests that variation around counties' means in degree days and precipitation leads to relatively small changes in profits per acres.

Both the degree day and precipitation marginal effects are virtually unchanged by the addition of the soil variables. This is reflected in the F-statistics, which easily fail to reject the null that the soil characteristics are jointly equal to zero. In this respect, this approach is preferable to the cross-sectional hedonic equations where the estimated effect of the climate variables on land values was sensitive to the inclusion of these controls. 
Table $6 \mathrm{~B}$ uses the $6 \mathrm{~A}$ results to develop estimates of the impact of the three climate change scenarios discussed above on agricultural profits. The estimates in each column are computed with the regression results from the specifications summarized in the same columns in $6 \mathrm{~A}$ (and the details are noted in the row headings at the bottom of the table). Due to the nonlinear modeling of the weather variables, each county's predicted impact is calculated as the discrete difference in per acre profits at the county's predicted degree days and precipitation after climate change and its current climate (i.e., the average over the 1970-2000 period). ${ }^{35}$ The resulting change in per acre profits is multiplied by the number of acres of farmland in the county and then the national effect is obtained by summing across all 2,262 counties in the sample. The climate parameters from the irrigated (dryland) counties are used to calculate the effect for the irrigated (dryland) counties.

We focus on the Hadley 2 Long Run scenario that allows for state-level variation in the change in degree days and precipitation. The preferred estimates from the specifications with state by year fixed effects suggest that climate change will lead to an increase of roughly $\$ 1.2$ billion in agricultural sector profits. This estimate is statistically indistinguishable from zero with either the Eicker-White (parentheses) or Conley (square brackets) standard errors. With the smaller standard errors, the 95\% confidence interval ranges from about $-\$ 1.9$ billion to $\$ 4.1$ billion. In the context of the mean annual profits of $\$ 32.3$ billion and range of $\$ 22.6$ to $\$ 42.1$ billion across Censuses, these estimates suggest that climate change will have a small effect on agricultural profits.

A few other features of the results are noteworthy. The effect is disproportionately due to the statistically significant increase in profits from the change in precipitation. Further if the point estimates are taken literally, the effect is almost entirely concentrated in dryland counties. ${ }^{36}$ The entries from the other scenarios follow a similar pattern with the columns (1) and (2) ones suggesting a small decline in profits and the specifications that include state by year fixed effects indicating a small increase. This finding that estimated profits are higher with state by year fixed effects suggests that local price changes do not appear to be a major concern in this context.

Panel A of Table 7 explores the robustness of the results to alternative specifications. All of the specifications include the soil variables and state by year fixed effects. The estimated impacts and their standard errors are from the Hadley 2 Long Run Scenario. The last column normalizes the predicted impact by mean annual profits to provide a sense of the magnitude.

\footnotetext{
${ }^{34}$ A Hausman type test easily rejects the null hypothesis that the estimated weather parameters for dryland counties are equal in the model with year fixed effects and the model with state by year fixed effects. The same null is also easily rejected for the irrigated counties.

${ }^{35}$ Since the Hadley 2 predictions are at the state level, each county is assigned its state's prediction

${ }^{36}$ We also estimated "fully interacted" models that allowed all parameters (e.g., the year or state by year fixed effects and soil parameters) to vary across irrigated and dryland counties. The estimated national impact of climate change is virtually unchanged in columns (1)-(4).
} 
The true functional form of the weather variables is unknown and thus far we have assumed that these variables are accurately modeled with a quadratic. Rows (1) through (3) model the weather variables linearly, with a cubic, and using indicator variables for each 500 degree days and 2 inch interval, respectively. ${ }^{37}$ The predicted change in profits is positive in all three of these approaches but a zero effect cannot be rejected in any of the cases.

Row (4) explores the possibility that the results in Table 6 are driven by outliers. Specifically, it presents the results from a robust regression routine. This routine begins by excluding outliers, defined as observations with values of Cook's $\mathrm{D}>1$, and then weights observations based on absolute residuals so that large residuals are downweighted. ${ }^{38}$ The entry indicates that the estimated impact is now negative, but the qualitative findings are unchanged.

Row (5) summarizes the results from estimating separate versions of equation (4) for each of the 48 states. Thus, all the parameters are allowed to vary at the state-level. The effect of the weather variables are allowed to vary across irrigated and dryland counties within each state. The sum of the state-specific estimates of the impact is roughly $-\$ 0.9$ billion. However, the heavy demands that this approach places on the data is evident in the poor precision of the estimate. ${ }^{39}$

The remaining rows of Panel [A] lead to the same qualitative conclusion that climate change will have only a modest effect on agricultural profits. Rows (6) through (8) indicate that the results are largely insensitive to how counties are assigned to the irrigated and dryland categories and whether the weather parameters are allowed to vary across these groups. In row (9) the growing season is extended by a month to include October and in row (10) we allow for two growing seasons that cover the entire year to allow for the effect of the important winter wheat crop. The predicted change remains small and

\footnotetext{
${ }^{37}$ In the indicator variable approach, the estimated impact is obtained by comparing predicted profits at each county's current degree day and precipitation categories and their degree day and precipitation categories that are predicted by the Hadley 2 long run scenario. A few counties are predicted to have growing season degree days and precipitation outside the range of the current data. To predict profits in these cases, we assign the average change in profits associated with a 1 category change (i.e., a change of 500 degree days or 2 inches) across the entire range of current data for each 500 degree day or 2 inch category increase. For example if a county is currently in the highest 500 degree day category and moves up two 500 degree day categories under the Hadley 2 scenario, its predicted increase in profits equals two times the average change in profits associated with an increase in a 500 degree category over the current range of data.

${ }^{38}$ After the outlier observations are excluded, the routine obtains optimal weights for the remaining observations in an iterative process. This process begins by taking the estimated residuals from the fitting of the linear regression and using them to obtain weights so that observations with large absolute residuals are downweighted. The regression is then fitted again using these weights and the residuals from this new regression are used to derive a new set of weights. This iterative procedure continues until the change in weights is below some threshold. Huber weights (Huber 1964) are used until convergence is achieved and then biweights (Beaton and Tukey 1974) are used until convergence is achieved with them. Street, Carroll, and Ruppert (1998) provide a method to calculate the standard errors. See Berk (1990) on robust regression.

${ }^{39}$ There are a total of 22 parameters so this model cannot be estimated separately for the 11 states with fewer than 22 counties in our sample. Instead, we group these states together in 2 groups (AZ, NV) and (CT, DE, MA, MD, $\mathrm{ME}, \mathrm{NH}, \mathrm{NJ}, \mathrm{RI}, \mathrm{VT}$ ) and estimate the model separately for each group.
} 
statistically insignificant in these rows. In row (11), the regression equation is not weighted and this increases the sampling error but leaves the basic conclusion unaltered.

Panel [B] aims to understand the source of the results better. Specifically, it separates farm profits into revenues and expenditures and uses them as separate dependent variables. The predicted changes are estimated imprecisely, but they suggest that revenues would increase by roughly $\$ 1$ billion and that expenses would be unchanged. The expenditures result implies that to the extent that farmers change their mix of inputs in response to weather shocks, these changes do not lead to a substantial increase in the costs of production. Government payments are not included in agricultural profits ${ }^{40}$, but the last row considers how climate change would affect this variable under the current federal programs. The results indicate a statistically significant increase of approximately $\$ 0.5$ billion.

Table 8 and Figure 6 provide an opportunity to explore the distributional consequences of climate change across states. Table 8 lists the predicted impact of the Hadley 2 long run climate change on statelevel agricultural profits. The states are ordered by the impact on profits and the percentage change in profits from largest to smallest in columns (1) and (2), respectively. The entries are based on the estimation of separate version of equation (4) for each state. The sum of these effects was presented in row (5) of Table 7.

The most striking finding is that California will be significantly harmed by climate change. Its loss in agricultural profits is $\$ 2.4$ billion and this is nearly $50 \%$ of total California agricultural profits. To place this estimate in further context, the remaining 47 states are predicted to have a gain of $\$ 1.5$ billion. Colorado (-\$610 million) and Oklahoma (-\$580 million) are also predicted to have big losses, while the two biggest winners are Pennsylvania (\$570 million) and South Dakota ( $\$ 540$ million). It would be remiss to fail to point out that in general these state-specific predictions are imprecise and the null of zero can be rejected at the 5\% level or better for only eight states (i.e., Delaware, Kansas, Massachusetts, New Mexico, New York, North Carolina, Pennsylvania, and South Dakota).

Figure 6 displays the geographic distribution of these impacts. The states in the highest quartile are colored black and those in the lowest quartile are light gray. The remaining $50 \%$ of states are denoted with dashed light gray. The dividing lines for these categories are $>\$ 167$ million, between $-\$ 122$ million and $\$ 167$ million, and $<-\$ 122$ million.

In general, the Northern parts of the US are predicted to do better than the Southern ones but the correlation is not perfect. For example, North Carolina and Florida are in the bottom quintile and South Carolina and Georgia are in the top quintile, although these four states are all in the South and in close proximity to each other. It is evident that climate change's impact on a state depends on the crop types

\footnotetext{
${ }^{40}$ The exception is that payments under the Commodity Credit Corporation are counted as part of revenues. These payments are in return for the delivery of crops to the federal government, so they differ from other subsidies.
} 
supported by its soil (North Carolina and Florida specialize in tobacco and citrus fruits) and its predicted change in climate (Figure 3B reveals that South Carolina and Georgia are in the top quintile of precipitation increases but the other states aren't).

Overall, the estimates in this subsection suggest that the predicted changes in climate would lead to economically small and statistically significant changes in profits. The preferred estimates suggest an increase in profits and have a 95\% confidence interval that ranges from a decline in profits of $\$ 1.9$ billion to an increase of $\$ 4.1$ billion, or $-5.7 \%$ to $12.3 \%$. Thus, it possible to reject large negative effects as has been suggested by some previous research. Further, it is important to recall that these figures may be downward biased relative to estimates that allow for the fuller range of adjustments available to farmers over longer time horizons.

\section{Estimates of the Response of Crop Yields to Climate Change}

In this subsection, we explore the effect of climate change on crop yields. This exercise complements the results from the previous one by assessing the effect of predicted climate change on crop yields. Large declines in yields would suggest that the profit results may be biased (relative to the preferred long run measure) by short run price increases. Although farmers cannot switch crops in response to weather shocks, they are able to undertake some adaptations and in this respect this approach is preferable to the production function approach.

Table 9 presents the results of versions of equation (4) where the dependent variables are countylevel total bushels of production per acre planted (production / acre planted) for corn for grain, soybeans, and wheat for grain. The independent variables of interest are growing season degree days and precipitation, both of which are modeled with a quadratic and allowed to vary among dryland and irrigated counties. The regressions all include controls for soil characteristics and county fixed effects and are weighted by the square root of the number of acres planted. The "a" specifications include year fixed effects and the "b" ones have state by year fixed effects. The sample is drawn from 1987, 1992, and 1997, and 2002 Censuses and for each crop it is limited to the counties with production of the crop in each of these years. These three crops account for roughly $\$ 46$ billion of revenues (in 2002 dollars, when their output is evaluated at the average crop price over these years), which is about $27 \%$ of total agricultural revenues.

The second panel reports the predicted change in national output in billion of bushels and its standard error under the Hadley 2 long run scenario. Due to the nonlinear modeling of the weather variables, each county's predicted change in bushels per acre is calculated as the discrete difference in per acre output at the county's predicted degree days and precipitation after climate change and its current climate (i.e., the average over the 1970-2000 period). The resulting change in bushels per acre is 
multiplied by the number of acres of farmland in the county and then the national effect is obtained by summing across all counties in the sample. The next row presents this change as a percentage of the average yield in our balanced sample of counties. The other rows report the change in bushels in dryland and irrigated counties and the separate impacts of the predicted changes in temperature and precipitation.

The results are consistent across the crops. Specifically, the more robust model with state by year fixed effects fails to find a statistically significant relationship between climate change and crop yields for any of the three crops. The less robust "a" specification finds negative effects for corn and soybeans, but they are small in magnitude. ${ }^{41}$ In general, the increase in temperature is harmful for yields and the increase in precipitation is beneficial. This finding underscores that it is important to account for both the change in temperature and precipitation when assessing the impacts of climate change. In summary, the small changes in output or quantities suggest that it is unlikely that the previous subsection's finding that climate change will have a small effect on agricultural profits is due to short-run price increases.

\section{Interpretation}

Optimal decisions about climate change policies require estimates of individuals' willingness to pay to avoid climate change over the long run. The above analysis has developed measures of the impact of climate change on the profits from agricultural operations that accrue to the owners of land. Since land values ultimately reflect the present discounted value of land rents, or profits from land, we use the estimates from the previous section to develop a measure of the welfare consequences of climate change. We assume that the predicted increase of $\$ 1.1$ billion (from column 4 of Table $6 \mathrm{~B}$ and the long run Hadley 2 model) in annual agricultural profits holds for all years in the future and apply a discount rate of $5 \%{ }^{42}$ This implies that climate change increases the present value of the stream of land rents by $\$ 22$ billion. The $95 \%$ confidence interval is $-\$ 36$ billion to $\$ 80$ billion. This range is much tighter than the range of estimates from the hedonic approach that did not even account for sampling variability.

There are a number of important caveats to these calculations and, more generally, to the analysis. First, some models of climate change predict increases in extreme events (e.g., droughts and floods) or the variance of climate realizations, in addition to any effects on growing season degree days and precipitation. Our analysis is uninformative about the economic impact of these events. If the predictions

\footnotetext{
${ }^{41}$ Lobell and Asner (2003a) find a negative relationship between county level corn and soybean yield trends and trends in mean temperatures. There are a number of differences between Lobell and Asner's approach and this paper's approach that make a comparisons of the results difficult, including Lobell and Asner: limit the sample to counties that exhibit a negative correlation between temperature and yields (see Gu 2003 and Lobell and Asner 2003b), do not adjust their estimates for state shocks (e.g., by including state fixed effects) or changes in precipitation; and use mean temperature over the growing season, rather than degree days.

${ }^{42}$ Some readers will prefer a higher discount rate, while others will prefer a lower one, and the implied change in the
} 
about these events are correct, a full accounting of the welfare effects of climate change would have to add the impacts of these changes to the impacts presented here. Similarly, it is thought that permanent changes in climate will disrupt local ecosystems and/or change soil quality. Both of these factors may affect agricultural productivity. Since annual fluctuations in climate are unlikely to have the same effect on ecosystems and soil quality as permanent changes, our estimates fail to account for these effects too.

Second as its name suggests, global climate change will affect agricultural production around the globe. It may be reasonable to assume that this will alter the long run costs of production and this would cause changes in relative prices. Since our estimates are based on annual fluctuations in weather and are adjusted for state by year fixed effects, it is unlikely that they fully account for this possibility. It is noteworthy that the hedonic approach is unable to account for such changes either because the land valueclimate gradient is estimated over the existing set of prices.

Third, there are a complex system of government programs that impact agricultural profits and land values by affecting farmers' decisions about which crops to plant, the amount of land to use, and the level of production (Kirwan 2004). Our estimates would likely differ if they were estimated with an alternative set of subsidy policies in force. This caveat also applies to the hedonic method.

Fourth, our measure of agricultural profits differs from an ideal one in some important respects. In particular, interest payments are the only measure of the rental cost of capital in the Censuses. This measure understates the cost of capital by not accounting for the opportunity cost of the portion of the capital stock that is not leveraged. Further, our measure of agricultural profits does not account for labor costs that are not compensated with wages (e.g., the labor provided by the farm owner).

Finally, we discuss two caveats to our approach that would lead to downward biased estimates of the impact of global warming, relative to an ideal measure. First as we have emphasized, our approach does not allow for the full set of adaptations available to farmers. We again note that this may cause the estimates from our preferred approach to be biased downwards, relative to a measure that allows for the full range of compensatory behaviors. The direction of the bias can be signed, because farmers will only undertake these adaptations if the present discounted value of the benefits are greater than the costs.

Second, elevated carbon dioxide $\left(\mathrm{CO}_{2}\right)$ concentrations are known to increase the yield per planted acre for many plants (see e.g., Miglietta, et. al. 1998). Since higher $\mathrm{CO}_{2}$ concentrations are thought to be a primary cause of climate change, it may be reasonable to assume that climate change will lead to higher yields per acre. The approach proposed in this paper does not account for this "fertilizing" effect of increased $\mathrm{CO}_{2}$ concentrations.

\section{Conclusions}

value of the stream of land rents can easily be adjusted to reflect such alternative assumptions (Weitzman 2001). 
This study proposes and implements a new strategy to estimate the impact of climate change on the US agricultural sector. The strategy exploits the presumably random year-to-year variation in temperature and precipitation to estimate their effect on agricultural profits. Specifically, we use a county-level panel data file constructed from the Censuses of Agriculture to estimate the effect of weather on agricultural profits, conditional on county and state by year fixed effects.

Using long-run climate change predictions from the Hadley 2 Model, the preferred estimates indicate that climate change will lead to a $\$ 1.1$ billion (2002\$) or 3.4\% increase in annual agricultural sector profits. The $95 \%$ confidence interval ranges from $-\$ 1.8$ billion to $\$ 4.0$ billion so large negative or positive effects are unlikely. The basic finding of an economically and statistically small effect is robust to a wide variety of specification checks including adjustment for the rich set of available controls, modeling temperature and precipitation flexibly, estimating separate regression equations for each state, and implementing a procedure that minimizes the influence of outliers. Additionally, the analysis indicates that the predicted increases in temperature and precipitation will have virtually no effect on yields among the most important crops (i.e., corn for grain, soybeans, and wheat for grain). These crop yield findings suggest that the small effect on profits is not due to short-run price increases.

Although the overall effect is small, there is considerable heterogeneity across the country. The most striking finding is that California will be substantially harmed by climate change. Its predicted loss in agricultural profits is $\$ 2.4$ billion and this is nearly $50 \%$ of current annual profits in California. Colorado (-\$610 million) and Oklahoma (-\$580 million) are also predicted to have big losses, while the two biggest winners are Pennsylvania (\$570 million) and South Dakota (\$540 million). It is important to note that these state-level estimates are demanding of the data and therefore less precise than is optimal.

Finally, we re-examines the hedonic approach that is predominant in the previous literature. We find that the estimates of the effect of climate change on the value of agricultural land range from -\$200 billion (1997\$) to $\$ 320$ billion (or $-24 \%$ to $39 \%$ ), which is an even wider range than has been noted in the previous literature. This variation in predicted impacts results from seemingly minor decisions about the appropriate control variables, sample, and weighting. Despite its theoretical appeal, we conclude that the hedonic method may be unreliable in this setting.

Our results indicate that there is room for much additional research in the valuation of climate change. For example, there is little research on the impact of climate change in non-agricultural regions and sectors. Future research should endeavor to produce estimates of the impact of climate change that have a sound theoretical basis and rely on credible identification assumptions. 


\section{Data Appendix}

\section{Covariates in Land Value and Agricultural Profits Regressions}

The following are the control variables used in the land value and agricultural profits regressions. They are listed by the categories indicated in the row headings at the bottom of these tables. All of the variables are measured at the county level.

Dependent Variables

Value of Land and Buildings per Acre

Agricultural Profits per Acre

Soil Variables

K-Factor of Top Soil

Slope Length

Fraction Flood-Prone

Fraction Sand

Fraction Clay

Fraction Irrigated

Permeability

Moisture Capacity

Wetlands

Salinity

Socioeconomic Variables

Income per Capita

Income per Capita squared

Population Density

Population Density Squared

Latitude

Latitude measured at county centroid

\section{Details on Data Sources}

\section{A. Census of Agriculture}

The data on number of farms, land in farms, cropland, agricultural profits, and other agriculture related variables are from the 1987, 1992, 1997, 2002 Censuses of Agriculture. The Census of Agriculture has been conducted every 5 years starting in 1925 and includes as a farm "every place from which $\$ 1,000$ or more of agricultural products were produced and sold or normally would have been sold during the census year". Participation in the Census of Agriculture is mandated by law: All farmers and ranchers who receive a census report form must respond even if they did not operate a farm or ranch in the census year. For confidentiality reasons the public-use files provide only county averages or totals.

The following are definitions for some specific variables that we used in the analysis:

Farm Revenues: Farm revenues are the gross market value of all agricultural products sold before taxes and expenses in the census year including livestock, poultry, and their products, and crops, including nursery and greenhouse crops, and hay. All sales occurring during the Census year are included, even if the payment has not been received.

Production Expenditures: Production expenses are limited to those incurred in the operation of the farm business. Property taxes paid by landlords are excluded. Also excluded were expenditures for non-farm 
activities, and farm-related activities such as producing and harvesting forest products, providing recreational services, and household expenses. Among the included items are: agricultural chemicals, commercial fertilizer, machine hire, rental of machinery and equipment, feed for livestock and poultry, hired farm and ranch labor, interest paid on debts, livestock and poultry purchased, repairs and maintenance, seed cost. All costs incurred during the Census year are included, regardless of whether the payment has been made.

Land in farms: The acreage designated as "land in farms" consists primarily of agricultural land used for crops, pasture, or grazing.

Value of land and buildings: Respondents were asked to report their estimate of the current market value of land and buildings owned, rented or leased from others, and rented or leased to others. Market value refers to the value the land and buildings would sell for under current market conditions.

B. National Resource Inventory

County-level data on soils are taken from the National Resource Inventory (http://www.nrcs.usda.gov/technical/NRI/). The NRI is a statistically based sample of land use and natural resource conditions and trends on U.S. nonfederal lands. The data has been collected in approximately 800,000 points during the Census of Agriculture years, starting in 1982. For example, information on soil permeability, salinity, soil contents (sand and clay), slope length, K-factor, and fraction of the county irrigated is available.

C. Hadley 2 State-Level and Regional Predictions on Growing Season Degree Days and Precipitation. We downloaded the raw climate data from The Vegetation/Ecosystem Modeling and Analysis Project (VEMAP)'s Transient Climate database. VEMAP was established as a project to learn more about ecosystem dynamics through models and simulations and involved a large number of American and foreign scientists from a variety of different organizations (Kittel et al. 1995; Kittel et al. 1997; Kittel et al. 2000). Phase 2 of VEMAP focused on transient dynamics, and the resulting database contains several climate change scenarios for the continental United States, including the predictions made by the Hadley 2 model. The climate variables included in this data set are accumulated monthly precipitation (in millimeters) and minimum and maximum temperature (in degrees Celsius). The data is given monthly from January 1994 to December 2099.

VEMAP measures climate data at a set of regular grid points spanning the contiguous United States and separated vertically and horizontally by $0.5^{\circ}$. The grid is then divided into 16 overlapping regions and separated into 16 files that must be downloaded individually. Although the climate data files do not give the latitude and longitude of the points that they contain, a different set of 16 files gives the coordinates of the points in each region. Since the points in the two regional files are given in the same order, we easily determined the latitude and longitude for each grid point in each region and then combined the 16 regional files into one larger file, eliminating the multiple instances of any points contained in more than one file.

We then used GIS software to place each of these gridpoints into U.S. states (and counties). With these placements, we were able to create the Hadley 2 state-level predictions for each month from 2000-2099. These state-level year by month predictions are calculated as the simple average across all grid points that fall within each state. These state-level Hadley 2 predictions are used to infer the economic costs of climate change throughout this paper. We focus on the "medium term" and "long run" effects on climate, which are defined as the temperature and precipitation averages across the 2020-2049 and 2070-2099 predictions, respectively. The Hadley 2 model is not precise enough to use at smaller units of aggregation than the state. 
D. Growing Season Degree Days

We construct our measure of growing season degree days using daily data drawn from the National Climatic Data Center (NCDC) Summary of the Day Data (TD-3200). The data are daily measurements from weather stations in the United States. In any given year in our sample period, there were approximately 8,000 stations in operation. The key variables used to construct degree days are the daily maximum and minimum temperature from each station. Using the daily minimum and maximum temperatures, we define the mean daily temperature as the simple average of the minimum and maximum temperature for a station. We then construct the mean daily temperature for a county by taking the simple average of the mean temperature across all stations within a county. For counties without a station, we impute the average mean temperature from the contiguous counties. The degree days variable is calculated on the daily mean temperature for each county as explained in the text in Section II. 


\section{References}

Adams, Richard M. (1989): "Global Climate Change and Agriculture: An Economic Perspective," American Journal of Agricultural Economics, 71: 1272-9.

Altonji, Joseph G., Todd E. Elder, and Christopher R. Taber (2000): "Selection on Observed and Unobserved Variables: Assessing the Effectiveness of Catholic School," NBER Working Paper \#7831.

Beaton, Albert E. and John W. Tukey. (1974): "The Fitting of Power Series, Meaning Polynomials, Illustrated on Band-Spectroscopic Data," Technometrics 16: 146-85.

Berk, Richard A. "A Primer on Robust Regression," in Modern Methods of Data Analysis. John Fox and J. Scott Long, eds., Newbury Park, CA: Sage Publications, 1990, 292-324.

Black, Dan A. and Thomas J. Kneisner (2003): "On the Measurement of Job Risk in Hedonic Wage Models," Journal of Risk and Uncertainty, 27(3): 205-20.

Black, Sandra (1999): "Do Better Schools Matter? Parental Valuation of Elementary Education," Quarterly Journal of Economics, 114.

Chay, Kenneth and Michael Greenstone (2005): "Does Air Quality Matter? Evidence from the Housing Market," Journal of Political Economy, 113(2): 376-424.

Cline, William R. (1996): "The Impact of Global Warming on Agriculture: Comment," American Economic Review, 86: 1309-1311.

Conley, Timothy, G. (1999): “GMM Estimation with Cross-Sectional Dependence," Journal of Econometrics, 92

Ekeland, Ivar, James J. Heckman, and Lars Nesheim (2004): "Identification and Estimation of Hedonic Models," Journal of Political Economy, forthcoming.

Greenstone, Michael and Justin Gallagher. (2005): "Does Hazardous Waste Matter? Evidence from the Housing Market and the Superfund Program.” MIT Economics Working Paper \#05-27.

Grierson, William. (2002): "Role of Temperature in the Physiology of Crop Plants: Pre- and PostHarvest," in Mohammed Pessarakli (editor), Handbook of Plant and Crop Physiology, New York: Marcel Dekker.

Gu, Lianhong (2003): "Comment on 'Climate and Management Contributions to Recent Trends in U.S. Agricultural Yields'," Science, 300: $1505 \mathrm{~b}$.

Hoch, Irving (1958): "Simultaneous Equations Bias in the Context of the Cobb-Douglass Production Function," Econometrica, 30: 566-578.

Hoch, Irving (1962): "Estimation of Production Function Parameters Combining Time Series and CrossSection Data," Econometrica, 30: 34-53.

Hodges, Tom, ed. (1991): Predicting Crop Phenology, Boca Raton: CRC Press, 1991.

Houghton, J.T., L.G. Meira Filho, B.A. Callender, N. Harris, A. Kattenberg, and K. Maskell, eds. (1996): 
Climate Change 1995: The Science of Climate Change. Contribution of Working Group I to the Second Assessment of the Intergovernmental Panel on Climate Change, Cambridge, England: Cambridge University Press.

Huber, Peter J. (1964): "Robust Estimation of a Location Parameter." Annals of Mathematical Statistics, 35: 73-101.

Intergovernmental Panel on Climate Change (1990): Climate Change: The IPCC Scientific Assessment (J. T. Houghton, G. J. Jenkins, and J. J. Ephraums, eds.), Cambridge: Cambridge University Press.

Johns, T. C., R. E. Carnell, J. F. Crossley, J. M. Gregory, J. F. B. Mitchell, C. A. Senior, S. F. B. Tett and R. A. Wood (1997): "The Second Hadley Centre Coupled Ocean-Atmosphere GCM: Model Description, Spinup and Validation," Climate Dynamics, 13: 103-134.

Kelly, David L., Charles D. Kolstad, and Glenn T. Mitchell (2005): "Adjustment Costs from Environmental Change," Journal of Environmental Economics and Management, 50(2): 468-495.

Kirwan, Barrett E. (2004): "The Incidence of U.S. Agriculture Subsidies on Farmland Rental Rates." Unpublished doctoral dissertation, MIT, Cambridge Massachusetts.

Kittel, T.G.F., N.A. Rosenbloom, T.H. Painter, D.S. Schimel, and VEMAP Modeling Participants (1995): "The VEMAP Integrated Database for Modeling United States Ecosystem/Vegetation Sensitivity to Climate Change," Journal of Biogeography, 22: 857-862.

Kittel, T.G.F., J.A. Royle, C. Daly, N.A. Rosenbloom, W.P. Gibson, H.H. Fisher, D.S. Schimel, L.M. Berliner, and VEMAP2 Participants (1997): "A Gridded Historical (1895-1993) Bioclimate Dataset for the Conterminous United States," in Proceedings of the 10th Conference on Applied Climatology, 20-24 October 1997, Reno, NV, Boston: American Meteorological Society.

Kittel, T.G.F., N.A. Rosenbloom, C. Kaufman, J.A. Royle, C. Daly, H.H. Fisher, W.P. Gibson, S. Aulenbach, R. McKeown, D.S. Schimel, and VEMAP2 Participants (2000): "VEMAP Phase 2 Historical and Future Scenario Climate Database." Available online at [http://www.cgd.ucar.edu/vemap] from the VEMAP Data Group, National Center for Atmospheric Research, Boulder, Colorado.

Lobell, David B. and Gregory P. Asner (2003a): "Climate and Management Contributions to Recent Trends in U.S. Agricultural Yields," Science, 299: 1032.

Lobell, David B. and Gregory P. Asner (2003b): "Response to Comment on 'Climate and Management Contributions to Recent Trends in U.S. Agricultural Yields',' Science, 300: 1505c.

Mendelsohn, Robert, William D. Nordhaus, and Daigee Shaw (1994): "The Impact of Global Warming on Agriculture: A Ricardian Approach,” American Economic Review, 84: 753-771.

Mendelsohn, Robert, William D. Nordhaus, and Daigee Shaw (1999): "The Impact of Climate Variation on U.S. Agriculture," in Robert Mendelsohn and James E. Neumann (editors), The Impact of Climate Change on the United States Economy, Cambridge University Press.

Miglietta, F., Magliulo, V., Bindi, M., Cerio, L., Vaccari, F.P., Loduca, V. and Peressotti, A. (1998): "Free Air $\mathrm{CO}_{2}$ Enrichment of Potato (Solanum tuberosum L.): Development, Growth and Yield," Global Change Biology 4: 163-172. 
Mundlak, Yair (1961): "Empirical Production Function Free of Management Bias," Journal of Farm Economics, 43: 44-56.

Mundlak, Yair (2001): "Production and Supply," in Handbook of Agricultural Economics, Volume 1A, Bruce L. Gardner and Gordon C. Rausser, eds., North-Holland: Amsterdam.

National Academy of Sciences Panel on Greenhouse Warming (1992): Policy Implications of Greenhouse Warming: Mitigation, Adaptation, and the Science Base, National Academy Press.

Plantinga, Andrew, Ruben Lubowski, and Robert Stavins (2002): "The Effects of Potential Land Development on Agricultural Land Prices." John F. Kennedy School of Government, Harvard University, Faculty Research Working Paper Series, RWP02-012.

Ritchie, J.T. and D. S. NeSmith (1991): "Temperature and Crop Development," in John Hanks and J.T. Ritchie (editors), Modeling Plant and Soil Systems, Madison, WI: American Society of Agronomy.

Rosen, Sherwin (1974): "Hedonic Prices and Implicit Markets: Product Differentiation in Pure Competition," Journal of Political Economy, 82: 34-55.

Schlenker, Wolfram, W. Michael Hanemann, and Anthony C. Fisher (2005a): "Will U.S. Agriculture Really Benefit from the Global Warming? Accounting for Irrigation in the Hedonic Approach," American Economic Review, 95(1): 395-406.

Schlenker, Wolfram, W. Michael Hanemann, and Anthony C. Fisher (2005b): "The Impact of Global Warming on U.S. Agriculture: An Econometric Analysis of Optimal Growing Conditions," Review of Economics and Statistics, forthcoming.

Street, James O., Raymond J. Carroll, and David Ruppert (1988): “A Note on Computing Robust Regression Estimates via Iteratively Weighted Least Squares,” The American Statistician 42: 152-4.

Thom, H. C. S. (1966): "Normal Degree Days Above Any Base by the Universal Truncation Coefficient," Monthly Weather Review, 94(7), 461-465.

United States Department of Agriculture, NASS (1997): "Usual Planting and Harvesting Dates for U.S. Field Crops," Agricultural Handbook, Number 628.

White, Halbert (1980): "A Heteroskedasticity-Consistent Covariance Matrix Estimator and A Direct Test for Heteroskedasticity,” Econometrica 48: 817-838.

Weitzman, Martin L. (2001): “Gamma Discounting,” American Economic Review, 91: 260-71. 
TABLE 1: COUNTY-LEVEL SUMMARY STATISTICS

\begin{tabular}{|c|c|c|c|c|c|c|}
\hline & 1978 & 1982 & 1987 & 1992 & 1997 & 2002 \\
\hline \multicolumn{7}{|l|}{ Farmland and Its Value: } \\
\hline Number of Farms & 799.3 & 796.3 & 745.4 & 688.3 & 684.9 & 766.5 \\
\hline Land in Farms (th. acres) & 363.7 & 352.4 & 345.5 & 338.4 & 333.4 & 336.1 \\
\hline Total Cropland (th. acres) & 158.7 & 156.0 & 158.3 & 155.9 & 154.1 & 155.3 \\
\hline Average Value of Land/Bldg (\$1/acre) & $1,370.4$ & $1,300.7$ & 907.3 & 892.2 & $1,028.2$ & $1,235.6$ \\
\hline Average Value of Machines/Equip (\$1/acre) & --- & --- & 126.7 & 118.8 & 129.2 & 145.8 \\
\hline \multicolumn{7}{|l|}{ Annual Financial Information: } \\
\hline Profits (\$Mil.) & --- & --- & 14.4 & 14.0 & 18.6 & 10.0 \\
\hline Profits Per Acre (\$1/acre) & --- & --- & 41.7 & 41.3 & 55.7 & 29.7 \\
\hline Farm Revenues (\$Mil.) & 88.7 & 80.0 & 71.5 & 72.9 & 79.9 & 74.9 \\
\hline Total Farm Expenses (\$Mil.) & --- & --- & 57.2 & 58.9 & 61.3 & 64.9 \\
\hline Total Government Payments (\$Mil.) & --- & --- & 4.8 & 2.3 & 1.9 & 2.4 \\
\hline \multicolumn{7}{|l|}{ Measures of Soil Productivity: } \\
\hline K-Factor & 0.30 & 0.30 & 0.30 & 0.30 & 0.30 & 0.30 \\
\hline Slope Length & 218.9 & 218.9 & 218.3 & 217.8 & 218.3 & 218.3 \\
\hline Fraction Flood-Prone & 0.15 & 0.15 & 0.15 & 0.15 & 0.15 & 0.15 \\
\hline Fraction Sand & 0.09 & 0.09 & 0.09 & 0.09 & 0.09 & 0.09 \\
\hline Fraction Clay & 0.18 & 0.18 & 0.18 & 0.18 & 0.18 & 0.18 \\
\hline Fraction Irrigated & 0.18 & 0.18 & 0.18 & 0.18 & 0.19 & 0.19 \\
\hline Permeability & 2.90 & 2.90 & 2.90 & 2.88 & 2.88 & 2.88 \\
\hline Moisture Capacity & 0.17 & 0.17 & 0.17 & 0.17 & 0.17 & 0.17 \\
\hline Wetlands & 0.10 & 0.10 & 0.10 & 0.10 & 0.10 & 0.10 \\
\hline Salinity & 0.01 & 0.01 & 0.01 & 0.01 & 0.01 & 0.01 \\
\hline \multicolumn{7}{|l|}{ Weather Variables: } \\
\hline January Temperature & 25.5 & 27.2 & 32.9 & 35.3 & 31.2 & 36.5 \\
\hline April Temperature & 54.3 & 51.0 & 54.7 & 53.6 & 49.9 & 56.1 \\
\hline July Temperature & 75.5 & 75.2 & 75.7 & 73.3 & 75.0 & 77.2 \\
\hline October Temperature & 55.6 & 55.9 & 53.0 & 55.4 & 56.0 & 54.4 \\
\hline January Precipitation & 3.73 & 3.34 & 2.68 & 2.48 & 2.85 & 2.48 \\
\hline April Precipitation & 2.86 & 3.10 & 1.99 & 2.42 & 3.53 & 2.90 \\
\hline July Precipitation & 3.57 & 3.62 & 3.37 & 4.61 & 3.19 & 3.22 \\
\hline October Precipitation & 1.38 & 2.49 & 1.30 & 1.95 & 2.89 & 4.12 \\
\hline Growing Season Degree Days & $2,865.2$ & $2,797.3$ & $2,934.2$ & $2,611.9$ & 2,757.4 & $3,116.3$ \\
\hline Growing Season Total Precipitation & 20.9 & 21.6 & 19.3 & 21.5 & 21.0 & 20.6 \\
\hline
\end{tabular}

Notes: Averages are calculated for a balanced panel of 2,268 counties. All entries are simple averages over the 2,268 counties, with the exception of “Average Value of Land/Bldg (1\$/acre)" and "Profit Per Acre (1\$/acre)", which are weighted by acres of farmland. All dollar values are in 2002 constant dollars. 
TABle 2: Climate Predictions under Different Global WARMing Models

\begin{tabular}{|c|c|c|c|c|c|c|}
\hline & \multicolumn{3}{|c|}{ Dryland Counties } & \multicolumn{3}{|c|}{ Irrigated Counties } \\
\hline & Actual & Predicted & Difference & Actual & Predicted & Difference \\
\hline \multicolumn{7}{|c|}{ BENCHMARK GLOBAL WARMING MODEL } \\
\hline January Mean Temperature & 29.0 & 34.0 & 5.0 & 32.9 & 37.9 & 5.0 \\
\hline April Mean Temperature & 51.9 & 56.9 & 5.0 & 52.3 & 57.3 & 5.0 \\
\hline July Mean Temperature & 74.7 & 79.7 & 5.0 & 74.3 & 79.3 & 5.0 \\
\hline October Mean Temperature & 54.3 & 59.3 & 5.0 & 55.1 & 60.1 & 5.0 \\
\hline January Precipitation & 1.57 & 1.70 & 0.13 & 1.92 & 2.08 & 0.15 \\
\hline April Total Precipitation & 2.40 & 2.60 & 0.19 & 2.08 & 2.25 & 0.17 \\
\hline July Total Precipitation & 2.82 & 3.05 & 0.23 & 2.27 & 2.45 & 0.18 \\
\hline October Total Precipitation & 2.23 & 2.41 & 0.18 & 1.73 & 1.87 & 0.14 \\
\hline Growing Season Degree Days & $3,184.8$ & $3,905.7$ & 720.9 & $3,289.1$ & $4,018.7$ & 729.5 \\
\hline Growing Season Total Precipitation & 16.96 & 18.32 & 1.36 & 13.60 & 14.68 & 1.09 \\
\hline \multicolumn{7}{|c|}{ HADLEY 2 GLOBAL WARMING MODEL } \\
\hline \multicolumn{7}{|c|}{ A. Medium Term (2020-2049) } \\
\hline Growing Season Degree Days: & $3,184.8$ & $3,964.1$ & 779.3 & 3,289.1 & $4,076.2$ & 787.0 \\
\hline Std Deviation & $(1,459.3)$ & $(1,325.6)$ & $(1,503.1)$ & $(1,503.4)$ & $(1,112.7)$ & $(1,376.2)$ \\
\hline Growing Season Total Precipitation: & 16.96 & 17.54 & 0.57 & 13.60 & 14.96 & 1.36 \\
\hline Std Deviation & $(6.74)$ & $(7.11)$ & $(4.25)$ & $(8.56)$ & $(7.50)$ & (3.99) \\
\hline \multicolumn{7}{|l|}{ B. Long Term (2070-2099) } \\
\hline \multicolumn{7}{|l|}{ Growing Season Degree Days: } \\
\hline All Counties [2262] & $3,184.8$ & 4,783.3 & $1,598.5$ & 3,289.1 & $4,951.3$ & $1,662.1$ \\
\hline Std Deviation & $(1,459.3)$ & $(1,736.8)$ & $(1,759.9)$ & $(1,503.4)$ & $(1,352.9)$ & $(1,505.1)$ \\
\hline Northeast Region [178] & $2,556.3$ & $4,221.9$ & $1,665.6$ & $3,581.7$ & $4,154.7$ & 573.0 \\
\hline Midwest Region [735] & $2,977.4$ & $3,760.3$ & 782.9 & $3,214.0$ & $4,263.5$ & $1,049.5$ \\
\hline South Region [986] & $4,097.6$ & $6,821.9$ & $2,724.3$ & $4,451.2$ & $6,702.2$ & $2,251.0$ \\
\hline West Region [363] & $2,581.6$ & $3,993.3$ & $1,411.7$ & $2,720.8$ & $4,405.1$ & $1,684.3$ \\
\hline \multicolumn{7}{|l|}{ Growing Season Total Precipitation: } \\
\hline All Counties [2262] & 16.96 & 19.34 & 2.38 & 13.60 & 16.26 & 2.66 \\
\hline Std Deviation & $(6.74)$ & (7.87) & $(4.62)$ & $(8.56)$ & $(8.34)$ & $(4.28)$ \\
\hline Northeast Region [178] & 23.38 & 27.64 & 4.26 & 24.04 & 27.40 & 3.36 \\
\hline Midwest Region [735] & 19.51 & 20.59 & 1.08 & 18.18 & 16.63 & -1.55 \\
\hline South Region [986] & 21.20 & 25.16 & 3.96 & 23.31 & 27.52 & 4.21 \\
\hline West Region [363] & 9.42 & 11.44 & 2.02 & 6.58 & 10.11 & 3.53 \\
\hline
\end{tabular}

Notes: All entries are averages over the 2,268 counties, weighted by acres of farmland. Entries under the "Actual” column are averages of the listed variables over the $1970-2000$ period. 
TABle 3: Deviations of Growing Season Degree Days and PRecipitation From Normals

\begin{tabular}{|c|c|c|c|c|c|c|c|c|}
\hline \multicolumn{9}{|c|}{ A. Removed Year Effects } \\
\hline \multirow[b]{2}{*}{ Degree Days } & \multicolumn{8}{|c|}{ Proportion of Counties with Degree Days Below/Above Average (Degrees): } \\
\hline & \pm 200 & \pm 400 & \pm 600 & \pm 800 & \pm 1000 & \pm 1200 & \pm 1400 & \pm 1600 \\
\hline 1987 & 0.48 & 0.23 & 0.12 & 0.07 & 0.05 & 0.02 & 0.02 & 0.01 \\
\hline 1992 & 0.53 & 0.30 & 0.20 & 0.12 & 0.05 & 0.02 & 0.01 & 0.00 \\
\hline 1997 & 0.43 & 0.17 & 0.08 & 0.05 & 0.03 & 0.01 & 0.01 & 0.00 \\
\hline \multirow[t]{2}{*}{2002} & 0.57 & 0.34 & 0.26 & 0.19 & 0.10 & 0.04 & 0.02 & 0.01 \\
\hline & \multicolumn{8}{|c|}{ Proportion of Counties with Precipitations Below/Above Average (Inches): } \\
\hline Total Precipitation & \pm 0.5 & \pm 1.0 & \pm 1.5 & \pm 2.0 & \pm 2.5 & \pm 3.0 & \pm 3.5 & \pm 4.0 \\
\hline 1987 & 0.86 & 0.71 & 0.57 & 0.46 & 0.35 & 0.25 & 0.19 & 0.15 \\
\hline 1992 & 0.83 & 0.65 & 0.51 & 0.39 & 0.31 & 0.24 & 0.18 & 0.12 \\
\hline 1997 & 0.85 & 0.70 & 0.55 & 0.42 & 0.31 & 0.23 & 0.16 & 0.12 \\
\hline 2002 & 0.84 & 0.70 & 0.56 & 0.45 & 0.35 & 0.28 & 0.22 & 0.16 \\
\hline \multicolumn{9}{|c|}{ B. Removed State*Year Effects } \\
\hline & \multicolumn{8}{|c|}{ Proportion of Counties with Degree Days Below/Above Average (Degrees): } \\
\hline Degree Days & \pm 200 & \pm 400 & \pm 600 & \pm 800 & \pm 1000 & \pm 1200 & \pm 1400 & \pm 1600 \\
\hline 1987 & 0.46 & 0.21 & 0.11 & 0.07 & 0.04 & 0.02 & 0.01 & 0.01 \\
\hline 1992 & 0.51 & 0.28 & 0.17 & 0.10 & 0.05 & 0.02 & 0.01 & 0.00 \\
\hline 1997 & 0.39 & 0.15 & 0.08 & 0.04 & 0.02 & 0.01 & 0.00 & 0.00 \\
\hline \multirow[t]{2}{*}{2002} & 0.56 & 0.35 & 0.24 & 0.16 & 0.08 & 0.03 & 0.02 & 0.01 \\
\hline & \multicolumn{8}{|c|}{ Proportion of Counties with Precipitations Below/Above Average (Inches): } \\
\hline Total Precipitation & \pm 0.5 & \pm 1.0 & \pm 1.5 & \pm 2.0 & \pm 2.5 & \pm 3.0 & \pm 3.5 & \pm 4.0 \\
\hline 1987 & 0.81 & 0.63 & 0.48 & 0.36 & 0.26 & 0.19 & 0.13 & 0.09 \\
\hline 1992 & 0.81 & 0.63 & 0.47 & 0.35 & 0.24 & 0.17 & 0.12 & 0.09 \\
\hline 1997 & 0.80 & 0.61 & 0.46 & 0.33 & 0.24 & 0.16 & 0.11 & 0.08 \\
\hline 2002 & 0.79 & 0.62 & 0.48 & 0.37 & 0.28 & 0.20 & 0.15 & 0.10 \\
\hline
\end{tabular}

Note: All statistics are weighted by acres of farmland. Panel A reports on the magnitude of the deviations between counties' yearly weather realizations and their long run averages after subtracting the deviation between the national average weather realization and the national long run average. The entries report the fraction of counties with deviations at least as large as the one reported in the column heading. For example, consider the 2002 degree days row, it indicates that $57 \%$, $19 \%$, and $2 \%$ of counties had deviations larger than 200, 800, and 1,400 degree days, respectively. Panel B repeats this exercise after subtracting the deviation between a states' yearly weather realization and the states' long run average (rather than the national deviation). 
TABLE 4A: SAMPLE MEANS By QuARTILES OF TEMPERATURE NORMALS

\begin{tabular}{|c|c|c|c|c|c|c|c|c|c|c|}
\hline \multirow[b]{2}{*}{ Quartile } & \multicolumn{5}{|c|}{ January Temperature Normals } & \multicolumn{5}{|c|}{ April Temperature Normals } \\
\hline & 1 & 2 & 3 & 4 & F-Stat & 1 & 2 & 3 & 4 & F-Stat \\
\hline \multicolumn{11}{|c|}{ Farmland values (\$1/ac): } \\
\hline Value of Land/Bldg & $1,196.9$ & $1,518.2$ & $1,403.3$ & $1,889.5$ & 20.7 & $1,040.5$ & $1,733.5$ & $1,802.0$ & $1,570.1$ & 52.6 \\
\hline \multicolumn{11}{|l|}{ Soil Characteristics: } \\
\hline K Factor & 0.30 & 0.33 & 0.33 & 0.28 & 39.3 & 0.30 & 0.32 & 0.33 & 0.29 & 23.9 \\
\hline Slope Length & 247.9 & 235.2 & 210.4 & 316.0 & 6.9 & 266.5 & 234.2 & 278.3 & 225.1 & 4.0 \\
\hline Fraction Flood-Prone & 0.10 & 0.14 & 0.19 & 0.19 & 14.3 & 0.11 & 0.13 & 0.20 & 0.18 & 12.4 \\
\hline Fraction Sand & 0.04 & 0.02 & 0.02 & 0.16 & 31.5 & 0.03 & 0.04 & 0.02 & 0.16 & 29.5 \\
\hline Fraction Clay & 0.21 & 0.16 & 0.20 & 0.36 & 28.5 & 0.19 & 0.19 & 0.22 & 0.34 & 15.4 \\
\hline Fraction Irrigated & 0.03 & 0.07 & 0.06 & 0.09 & 12.8 & 0.04 & 0.07 & 0.08 & 0.06 & 6.7 \\
\hline Permeability & 2.24 & 1.92 & 2.05 & 3.51 & 20.0 & 2.13 & 2.12 & 2.04 & 3.55 & 17.6 \\
\hline Moisture Capacity & 0.18 & 0.19 & 0.17 & 0.14 & 145.0 & 0.18 & 0.19 & 0.17 & 0.14 & 88.5 \\
\hline Wetlands & 0.07 & 0.04 & 0.04 & 0.11 & 43.3 & 0.07 & 0.03 & 0.04 & 0.12 & 55.7 \\
\hline Salinity & 0.05 & 0.02 & 0.01 & 0.03 & 12.1 & 0.05 & 0.02 & 0.02 & 0.02 & 14.4 \\
\hline \multicolumn{11}{|c|}{ Socioeconomic and Locational Attributes: } \\
\hline Pop Density & 33.0 & 65.4 & 50.5 & 95.1 & 17.9 & 28.1 & 67.8 & 84.8 & 72.4 & 27.4 \\
\hline Per Capita Income & 16,573 & 16,755 & 15,136 & 15,280 & 15.4 & 16,432 & 16,648 & 16,193 & 14,525 & 20.8 \\
\hline \multirow[t]{2}{*}{ Latitude } & 44.54 & 40.63 & 36.74 & 32.35 & 854.0 & 44.51 & 40.37 & 36.62 & 31.84 & 1108.9 \\
\hline & \multicolumn{5}{|c|}{ July Temperature Normals } & \multicolumn{5}{|c|}{ October Temperature Normals } \\
\hline Quartile & 1 & 2 & 3 & 4 & F-Stat & 1 & 2 & 3 & 4 & F-Stat \\
\hline \multicolumn{11}{|c|}{ Farmland values (\$1/ac): } \\
\hline Value of Land/Bldg & $1,120.0$ & $1,775.6$ & $1,606.9$ & $1,506.0$ & 26.0 & $1,018.5$ & $1,816.8$ & $1,653.9$ & $1,728.5$ & 60.3 \\
\hline \multicolumn{11}{|l|}{ Soil Characteristics: } \\
\hline K Factor & 0.32 & 0.30 & 0.32 & 0.30 & 13.8 & 0.31 & 0.31 & 0.33 & 0.29 & 20.2 \\
\hline Slope Length & 280.5 & 245.5 & 255.6 & 218.9 & 5.0 & 270.5 & 218.0 & 230.5 & 275.0 & 9.8 \\
\hline Fraction Flood-Prone & 0.12 & 0.13 & 0.17 & 0.19 & 7.1 & 0.11 & 0.14 & 0.17 & 0.20 & 12.3 \\
\hline Fraction Sand & 0.03 & 0.05 & 0.03 & 0.14 & 23.9 & 0.03 & 0.04 & 0.03 & 0.15 & 24.1 \\
\hline Fraction Clay & 0.18 & 0.21 & 0.21 & 0.33 & 16.1 & 0.18 & 0.20 & 0.20 & 0.35 & 22.8 \\
\hline Fraction Irrigated & 0.05 & 0.06 & 0.07 & 0.06 & 3.4 & 0.04 & 0.06 & 0.06 & 0.08 & 6.0 \\
\hline Permeability & 2.05 & 2.34 & 2.04 & 3.28 & 15.8 & 2.14 & 2.09 & 2.11 & 3.43 & 15.2 \\
\hline Moisture Capacity & 0.17 & 0.18 & 0.18 & 0.15 & 63.6 & 0.18 & 0.19 & 0.17 & 0.14 & 81.4 \\
\hline Wetlands & 0.06 & 0.05 & 0.05 & 0.10 & 23.4 & 0.07 & 0.04 & 0.04 & 0.11 & 41.4 \\
\hline Salinity & 0.05 & 0.04 & 0.01 & 0.02 & 13.7 & 0.05 & 0.01 & 0.01 & 0.02 & 16.8 \\
\hline \multicolumn{11}{|c|}{ Socioeconomic and Locational Attributes: } \\
\hline Pop Density & 30.2 & 84.3 & 59.4 & 67.6 & 21.3 & 21.0 & 83.5 & 62.5 & 92.2 & 50.2 \\
\hline Per Capita Income & 16,583 & 16,483 & 16,118 & 14,741 & 17.8 & 16,319 & 16,813 & 15,989 & 14,857 & 12.7 \\
\hline Latitude & 44.33 & 40.83 & 37.18 & 32.47 & 678.6 & 44.57 & 39.97 & 36.63 & 32.15 & 951.7 \\
\hline
\end{tabular}

Notes: All dollar figures in 2002 constant dollars. The entries report the results of weighted regressions where the dependent variable is noted in the row headings and the weight is the square root of the acres of farmland. The entries are the parameter estimates from dummy variables for quartiles of the relevant climate normal, so they report the mean of each variable by quartile. Climate normals are defined as the 1970-2000 average of temperature and precipitation, by county. The F-statistics are from tests of equality of the means across the quartiles. The regressions are fit with data from the 1978, 1982, 1987, 1992, 1997, and 2002 Censuses, so they adjust for year fixed effects to account for national differences across years. The variance-covariance matrix allows for a county-specific variance component. See the text for further details. 
TABle 4B: SAMPle MeAns by Quartiles of Precipitations NoRMals

\begin{tabular}{|c|c|c|c|c|c|c|c|c|c|c|}
\hline \multirow[b]{2}{*}{ Quartile } & \multicolumn{5}{|c|}{ January Precipitation Normals } & \multicolumn{5}{|c|}{ April Precipitation Normals } \\
\hline & 1 & 2 & 3 & 4 & F-Stat & 1 & 2 & 3 & 4 & F-Stat \\
\hline \multicolumn{11}{|c|}{ Farmland values (\$1/ac): } \\
\hline Value of Land/Bldg & 914.3 & $1,708.4$ & $2,366.4$ & $2,228.5$ & 217.2 & $1,026.7$ & $1,717.3$ & $2,335.8$ & $1,962.7$ & 148.9 \\
\hline \multicolumn{11}{|l|}{ Soil Characteristics: } \\
\hline K Factor & 0.30 & 0.32 & 0.32 & 0.29 & 15.0 & 0.31 & 0.29 & 0.31 & 0.35 & 90.7 \\
\hline Slope Length & 261.3 & 258.4 & 244.9 & 209.6 & 3.2 & 312.0 & 195.9 & 189.4 & 164.7 & 46.1 \\
\hline Fraction Flood-Prone & 0.12 & 0.15 & 0.19 & 0.22 & 12.6 & 0.13 & 0.12 & 0.13 & 0.27 & 35.1 \\
\hline Fraction Sand & 0.03 & 0.06 & 0.06 & 0.18 & 29.3 & 0.05 & 0.11 & 0.07 & 0.02 & 42.5 \\
\hline Fraction Clay & 0.26 & 0.21 & 0.18 & 0.19 & 6.3 & 0.23 & 0.27 & 0.20 & 0.16 & 11.8 \\
\hline Fraction Irrigated & 0.05 & 0.05 & 0.08 & 0.08 & 4.5 & 0.08 & 0.05 & 0.02 & 0.05 & 40.1 \\
\hline Permeability & 2.13 & 2.28 & 2.59 & 3.65 & 18.9 & 2.32 & 2.99 & 2.52 & 1.75 & 28.3 \\
\hline Moisture Capacity & 0.18 & 0.18 & 0.16 & 0.15 & 50.3 & 0.17 & 0.17 & 0.18 & 0.18 & 19.8 \\
\hline Wetlands & 0.04 & 0.06 & 0.08 & 0.17 & 73.2 & 0.04 & 0.09 & 0.09 & 0.10 & 49.8 \\
\hline Salinity & 0.04 & 0.02 & 0.01 & 0.01 & 25.7 & 0.05 & 0.01 & 0.00 & 0.00 & 45.7 \\
\hline \multicolumn{11}{|c|}{ Socioeconomic and Locational Attributes: } \\
\hline Pop Density & 13.4 & 80.8 & 139.2 & 101.2 & 94.9 & 24.9 & 72.3 & 138.2 & 85.5 & 62.1 \\
\hline Per Capita Income & 16,087 & 16,236 & 16,364 & 14,976 & 8.0 & 15,963 & 16,670 & 16,940 & 14,340 & 64.9 \\
\hline \multirow[t]{2}{*}{ Latitude } & 41.12 & 38.86 & 37.11 & 34.96 & 97.8 & 40.63 & 38.41 & 38.42 & 35.97 & 86.5 \\
\hline & \multicolumn{5}{|c|}{ July Precipitation Normals } & \multicolumn{5}{|c|}{ October Precipitation Normals } \\
\hline Quartile & 1 & 2 & 3 & 4 & F-Stat & 1 & 2 & 3 & 4 & F-Stat \\
\hline \multicolumn{11}{|c|}{ Farmland values (\$1/ac): } \\
\hline Value of Land/Bldg & $1,115.4$ & $1,402.6$ & $2,233.6$ & $2,166.2$ & 139.5 & $1,030.7$ & $1,994.9$ & $1,957.2$ & $1,926.8$ & 110.7 \\
\hline \multicolumn{11}{|l|}{ Soil Characteristics: } \\
\hline K Factor & 0.32 & 0.30 & 0.32 & 0.25 & 38.6 & 0.31 & 0.29 & 0.30 & 0.33 & 25.2 \\
\hline Slope Length & 325.6 & 194.2 & 185.6 & 161.4 & 53.9 & 309.6 & 210.5 & 181.3 & 169.1 & 44.3 \\
\hline Fraction Flood-Prone & 0.16 & 0.14 & 0.16 & 0.12 & 3.9 & 0.14 & 0.08 & 0.16 & 0.24 & 52.5 \\
\hline Fraction Sand & 0.03 & 0.04 & 0.03 & 0.28 & 45.3 & 0.03 & 0.11 & 0.11 & 0.04 & 26.3 \\
\hline Fraction Clay & 0.29 & 0.17 & 0.21 & 0.10 & 35.2 & 0.22 & 0.25 & 0.15 & 0.29 & 14.6 \\
\hline Fraction Irrigated & 0.07 & 0.06 & 0.02 & 0.04 & 18.7 & 0.08 & 0.02 & 0.02 & 0.05 & 29.0 \\
\hline Permeability & 1.93 & 2.36 & 1.89 & 5.23 & 49.6 & 2.14 & 2.89 & 3.03 & 2.15 & 12.6 \\
\hline Moisture Capacity & 0.16 & 0.19 & 0.19 & 0.15 & 122.7 & 0.17 & 0.18 & 0.16 & 0.16 & 12.6 \\
\hline Wetlands & 0.03 & 0.07 & 0.10 & 0.17 & 143.7 & 0.04 & 0.09 & 0.10 & 0.11 & 80.5 \\
\hline Salinity & 0.05 & 0.02 & 0.00 & 0.00 & 46.7 & 0.05 & 0.01 & 0.01 & 0.01 & 35.1 \\
\hline \multicolumn{11}{|c|}{ Socioeconomic and Locational Attributes: } \\
\hline Pop Density & 33.6 & 51.0 & 117.0 & 104.8 & 47.3 & 21.2 & 97.0 & 99.9 & 102.6 & 67.8 \\
\hline Per Capita Income & 15,835 & 16,391 & 16,665 & 15,260 & 11.0 & 16,299 & 16,300 & 15,415 & 15,370 & 8.1 \\
\hline Latitude & 39.50 & 40.49 & 39.74 & 34.84 & 88.5 & 41.59 & 38.80 & 36.40 & 34.39 & 154.3 \\
\hline
\end{tabular}

Notes: See notes to Table 4A. 
TABle 5: Hedonic Estimates of IMPACt of Benchmark Climate Change Scenario on AGRICULTURAL LAND VALUES (IN BILLIONS OF 2002 DOLLARS), 1978-2002

\begin{tabular}{|c|c|c|c|c|c|c|c|c|}
\hline \multirow{2}{*}{$\begin{array}{l}\text { Specification: } \\
\text { Weights: }\end{array}$} & \multicolumn{2}{|c|}{ A } & \multicolumn{2}{|c|}{ B } & \multicolumn{2}{|c|}{ C } & \multicolumn{2}{|c|}{$\mathrm{D}$} \\
\hline & [0] & [1] & {$[0]$} & [1] & [0] & [1] & [0] & [1] \\
\hline \multicolumn{9}{|l|}{ Single Census Year } \\
\hline 1978 & $\begin{array}{l}131.9 \\
(49.0)\end{array}$ & $\begin{array}{l}131.1 \\
(48.4)\end{array}$ & $\begin{array}{l}141.2 \\
(51.5)\end{array}$ & $\begin{array}{l}154.7 \\
(42.6)\end{array}$ & $\begin{array}{l}321.3 \\
(59.0)\end{array}$ & $\begin{array}{l}255.6 \\
(41.8)\end{array}$ & $\begin{array}{l}288.7 \\
(66.8)\end{array}$ & $\begin{array}{l}174.9 \\
(45.2)\end{array}$ \\
\hline 1982 & $\begin{array}{c}36.3 \\
(40.0)\end{array}$ & $\begin{array}{c}36.1 \\
(35.9)\end{array}$ & $\begin{array}{c}19.2 \\
(40.3)\end{array}$ & $\begin{array}{c}40.8 \\
(34.7)\end{array}$ & $\begin{array}{l}203.3 \\
(56.0)\end{array}$ & $\begin{array}{l}154.6 \\
(38.8)\end{array}$ & $\begin{array}{l}217.6 \\
(66.5)\end{array}$ & $\begin{array}{c}80.8 \\
(49.9)\end{array}$ \\
\hline 1987 & $\begin{array}{l}-55.9 \\
(35.8)\end{array}$ & $\begin{array}{c}-9.6 \\
(29.9)\end{array}$ & $\begin{array}{l}-49.3 \\
(37.4)\end{array}$ & $\begin{array}{c}-8.7 \\
(28.0)\end{array}$ & $\begin{array}{c}45.9 \\
(47.4)\end{array}$ & $\begin{array}{c}51.3 \\
(28.0)\end{array}$ & $\begin{array}{c}47.8 \\
(54.3)\end{array}$ & $\begin{array}{c}13.3 \\
(32.6)\end{array}$ \\
\hline 1992 & $\begin{array}{l}-50.4 \\
(48.3)\end{array}$ & $\begin{array}{l}-23.0 \\
(43.3)\end{array}$ & $\begin{array}{l}-32.9 \\
(44.0)\end{array}$ & $\begin{array}{c}-8.1 \\
(33.9)\end{array}$ & $\begin{array}{c}22.3 \\
(59.1)\end{array}$ & $\begin{array}{c}46.4 \\
(30.2)\end{array}$ & $\begin{array}{c}17.1 \\
(65.0)\end{array}$ & $\begin{array}{c}8.4 \\
(32.9)\end{array}$ \\
\hline 1997 & $\begin{array}{l}-117.0 \\
(43.3)\end{array}$ & $\begin{array}{l}-55.5 \\
(48.7)\end{array}$ & $\begin{array}{l}-89.0 \\
(45.7)\end{array}$ & $\begin{array}{l}-33.5 \\
(39.5)\end{array}$ & $\begin{array}{c}25.5 \\
(54.3)\end{array}$ & $\begin{array}{c}65.8 \\
(29.4)\end{array}$ & $\begin{array}{c}78.1 \\
(60.7)\end{array}$ & $\begin{array}{c}40.3 \\
(33.4)\end{array}$ \\
\hline 2002 & $\begin{array}{l}-288.6 \\
(79.9)\end{array}$ & $\begin{array}{l}-139.5 \\
(78.2)\end{array}$ & $\begin{array}{l}-202.1 \\
(75.9)\end{array}$ & $\begin{array}{l}-101.0 \\
(62.3)\end{array}$ & $\begin{array}{c}-8.8 \\
(88.5)\end{array}$ & $\begin{array}{c}60.9 \\
(47.0)\end{array}$ & $\begin{array}{l}17.7 \\
(93.2)\end{array}$ & $\begin{array}{c}13.2 \\
(50.1)\end{array}$ \\
\hline \multicolumn{9}{|l|}{ Pooled 1978-2002 } \\
\hline All Counties & $\begin{array}{l}-68.1 \\
(38.1)\end{array}$ & $\begin{array}{l}-15.5 \\
(39.7)\end{array}$ & $\begin{array}{l}-42.2 \\
(40.2)\end{array}$ & $\begin{array}{c}0.4 \\
(34.2)\end{array}$ & $\begin{array}{c}86.9 \\
(48.6)\end{array}$ & $\begin{array}{l}101.9 \\
(28.3)\end{array}$ & $\begin{array}{l}114.6 \\
(52.4)\end{array}$ & $\begin{array}{c}67.0 \\
(31.3)\end{array}$ \\
\hline Dryland Counties & $\begin{array}{l}-61.9 \\
(24.3)\end{array}$ & $\begin{array}{l}-26.6 \\
(28.5)\end{array}$ & $\begin{array}{l}-42.9 \\
(28.0)\end{array}$ & $\begin{array}{c}-9.9 \\
(24.6)\end{array}$ & $\begin{array}{c}61.9 \\
(35.5)\end{array}$ & $\begin{array}{c}78.0 \\
(17.9)\end{array}$ & $\begin{array}{c}85.2 \\
(38.8)\end{array}$ & $\begin{array}{c}48.9 \\
(21.3)\end{array}$ \\
\hline Irrigated Counties & $\begin{array}{c}-6.2 \\
(13.8)\end{array}$ & $\begin{array}{c}11.1 \\
(11.2)\end{array}$ & $\begin{array}{c}0.7 \\
(12.2)\end{array}$ & $\begin{array}{l}10.2 \\
(9.7)\end{array}$ & $\begin{array}{c}25.0 \\
(13.1)\end{array}$ & $\begin{array}{c}23.9 \\
(10.4)\end{array}$ & $\begin{array}{c}29.4 \\
(13.6)\end{array}$ & $\begin{array}{c}18.1 \\
(10.0)\end{array}$ \\
\hline Soil Variables & No & No & Yes & Yes & Yes & Yes & Yes & Yes \\
\hline Socioecon. Vars & No & No & Yes & Yes & Yes & Yes & Yes & Yes \\
\hline State Fixed-Effects & No & No & No & No & Yes & Yes & Yes & Yes \\
\hline Latitude & No & No & No & No & No & No & Yes & Yes \\
\hline
\end{tabular}

Notes: All dollar figures in billions of 2002 constant dollars. The entries are the predicted impact on agricultural land values of the benchmark uniform increases of 5 degree Fahrenheit and 8\% precipitation from the estimation of 56 different hedonic models, noted as equation (3) in the text. The standard errors of the predicted impacts are reported in parentheses. The 56 different sets of estimates of the national impact on land values are the result of 7 different data samples, 4 specifications, and 2 assumptions about the correct weights. The data samples are denoted in the row headings. There is a separate sample for each of the Census years and the seventh is the result of pooling data from the six Censuses. The specification details are noted in the row headings at the bottom of the table. The weights used in the regressions are reported in the top row and are as follows: [0]=unweighted; [1]=square root of acres of farmland. The estimated impacts are reported separately for dryland and irrigated counties for the pooled sample. See the text for further details. 


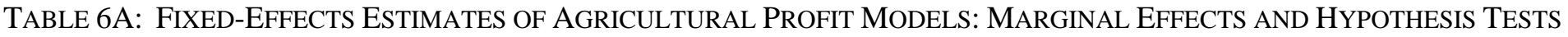

\begin{tabular}{|c|c|c|c|c|}
\hline & $(1)$ & $(2)$ & $(3)$ & $(4)$ \\
\hline 1(Dryland) * Growing Season Degree Days & $\begin{array}{c}-0.0018 \\
(0.0007)\end{array}$ & $\begin{array}{l}-0.0019 \\
(0.0008)\end{array}$ & $\begin{array}{c}0.0015 \\
(0.0006)\end{array}$ & $\begin{array}{c}0.0016 \\
(0.0006)\end{array}$ \\
\hline 1(Irrigated) * Growing Season Degree Days & $\begin{array}{l}-0.0049 \\
(0.0024)\end{array}$ & $\begin{array}{l}-0.0049 \\
(0.0024)\end{array}$ & $\begin{array}{l}-0.0026 \\
(0.0022)\end{array}$ & $\begin{array}{c}-0.0026 \\
(0.0022)\end{array}$ \\
\hline 1(Dryland) * Growing Season Total Precip & $\begin{array}{c}-0.3586 \\
(0.1014)\end{array}$ & $\begin{array}{c}-0.3536 \\
(0.1015)\end{array}$ & $\begin{array}{c}0.1675 \\
(0.1065)\end{array}$ & $\begin{array}{c}0.1721 \\
(0.1075)\end{array}$ \\
\hline 1 (Irrigated) * Growing Season Total Precip & $\begin{array}{c}0.6568 \\
(0.3975)\end{array}$ & $\begin{array}{c}0.6583 \\
(0.3968)\end{array}$ & $\begin{array}{c}1.1759 \\
(0.3858)\end{array}$ & $\begin{array}{c}1.2104 \\
(0.3875)\end{array}$ \\
\hline \multicolumn{5}{|c|}{ P-Values from Tests of Equality of Marginal Effects by Irrigation Status: } \\
\hline Degree Days & 0.165 & 0.173 & 0.054 & 0.047 \\
\hline Total Precip & 0.012 & 0.012 & 0.009 & 0.007 \\
\hline \multicolumn{5}{|c|}{ P-Values from Tests that Listed Variables are Jointly Equal to Zero: } \\
\hline Soil Characteristics: & --- & 0.162 & --- & 0.542 \\
\hline County Fixed Effects & 0.001 & 0.001 & 0.001 & 0.001 \\
\hline Year Fixed Effects & 0.001 & 0.001 & --- & --- \\
\hline State by Year Fixed Effects & --- & --- & 0.001 & 0.001 \\
\hline Soil Controls & No & Yes & No & Yes \\
\hline County Fixed Effects & Yes & Yes & Yes & Yes \\
\hline Year Fixed Effects & Yes & Yes & No & No \\
\hline State*Year Fixed Effects & No & No & Yes & Yes \\
\hline
\end{tabular}

Notes: All dollar figures in 2002 constant dollars. The entries in the first panel are the result of the estimation of version of equation (4) for agricultural profits that model the growing season degree days and total precipitation with quadratics. The marginal effects and their heteroskedastic standard errors (in parentheses) of the weather variable are reported. The marginal effects are evaluated at the mean of growing season degree days and growing season total precipitation. These calculations are done separately by irrigation status. The second and third panels report p-values from F-tests that subsets of the variables are jointly equal to zero. The controls are listed in the row headings at the bottom of the table. See the text for further details. 
TABle 6B: Fixed-Effects Estimates of Agricultural Profit Models: Predicted Impact of Three Global Warming Scenarios (in BILLIONS OF 2002 DOLLARS)

\begin{tabular}{|c|c|c|c|c|}
\hline & $(1)$ & $(2)$ & $(3)$ & $(4)$ \\
\hline \multicolumn{5}{|l|}{ A. Benchmark Climate Change Model: } \\
\hline All Counties & $\begin{array}{l}-1.56 \\
(0.49) \\
{[0.71]}\end{array}$ & $\begin{array}{l}-1.59 \\
(0.50) \\
{[0.71]}\end{array}$ & $\begin{array}{c}0.78 \\
(0.44) \\
{[0.74]}\end{array}$ & $\begin{array}{c}0.83 \\
(0.44) \\
{[0.74]}\end{array}$ \\
\hline \multicolumn{5}{|c|}{ B. Hadley 2 Climate $\mathrm{Change} \mathrm{M}$ odel Medium Term (2020-2049): } \\
\hline All Counties & $\begin{array}{c}-0.83 \\
(0.75) \\
{[1.15]}\end{array}$ & $\begin{array}{l}-0.88 \\
(0.76) \\
{[1.15]}\end{array}$ & $\begin{array}{c}0.60 \\
(0.72) \\
{[1.16]}\end{array}$ & $\begin{array}{c}0.51 \\
(0.73) \\
{[1.16]}\end{array}$ \\
\hline \multicolumn{5}{|c|}{ C. Hadley 2 Climate Change Model Long Term (2070-2099) } \\
\hline All Counties & $\begin{array}{c}-1.98 \\
(1.54) \\
{[2.35]}\end{array}$ & $\begin{array}{l}-2.09 \\
(1.55) \\
{[2.35]}\end{array}$ & $\begin{array}{c}1.27 \\
(1.47) \\
{[2.37]}\end{array}$ & $\begin{array}{l}1.10 \\
(1.48) \\
{[2.37]}\end{array}$ \\
\hline Dryland Counties: & $\begin{array}{l}-1.76 \\
(1.21)\end{array}$ & $\begin{array}{l}-1.88 \\
(1.22)\end{array}$ & $\begin{array}{c}1.29 \\
(1.15)\end{array}$ & $\begin{array}{c}1.13 \\
(1.16)\end{array}$ \\
\hline Irrigated Counties: & $\begin{array}{c}-0.22 \\
(0.86)\end{array}$ & $\begin{array}{l}-0.20 \\
(0.86)\end{array}$ & $\begin{array}{c}-0.02 \\
(0.78)\end{array}$ & $\begin{array}{l}-0.03 \\
(0.78)\end{array}$ \\
\hline Impact of Change in Degree Days & $\begin{array}{l}-1.67 \\
(1.52)\end{array}$ & $\begin{array}{l}-1.80 \\
(1.53)\end{array}$ & $\begin{array}{c}0.53 \\
(1.45)\end{array}$ & $\begin{array}{c}0.34 \\
(1.46)\end{array}$ \\
\hline Impact of Change in Total Precipitation & $\begin{array}{l}-0.31 \\
(0.35)\end{array}$ & $\begin{array}{l}-0.29 \\
(0.34)\end{array}$ & $\begin{array}{c}0.74 \\
(0.25)\end{array}$ & $\begin{array}{c}0.76 \\
(0.25)\end{array}$ \\
\hline Soil Controls & $\mathrm{No}$ & Y es & No & Y es \\
\hline County Fixed Effects & Y es & Y es & Y es & Y es \\
\hline Year Fixed Effects & Y es & Y es & No & No \\
\hline State*Year Fixed Effects & $\mathrm{No}$ & $\mathrm{No}$ & Y es & Y es \\
\hline
\end{tabular}

Notes: All dollar figures in billions of 2002 constant dollars. This table report predicted impacts of climate change on agricultural profits using the estimation results from the fitting of versions of equation (4) (summarized in Table 6A) and three climate change scenarios. The impacts' heteroskedastic consistent standard errors are in parentheses and the Conley ones are in square brackets. Due to the nonlinear modeling of the weather variables, each county's predicted impact is calculated as the discrete difference in per acre profits at the county's predicted degree days and precipitation after climate change and its current climate (i.e., the average over the 1970-2000 period). The resulting change in per acre profits is multiplied by the number of acres of farmland in the county and then the national effect is obtained by summing across all 2,262 counties in the sample. The climate parameters from the irrigated (dryland) counties are used to calculate the effect for the irrigated (dryland) counties. The specifications correspond to the ones in Table 6A and the exact controls are listed at the bottom of the table. See Table 6A and the text for further details. 


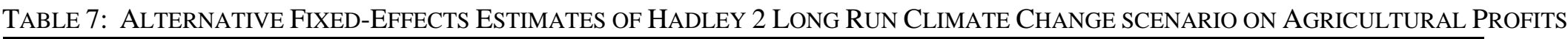

\begin{tabular}{|c|c|c|c|}
\hline & \multicolumn{3}{|c|}{ Hadley 2 Long Run (2070-2099) } \\
\hline & $\begin{array}{l}\text { Predicted Change } \\
\text { (Billion dollars) }\end{array}$ & Standard Error & Percent Effect \\
\hline \multicolumn{4}{|l|}{$\begin{array}{l}\text { [A] Alternative Specifications } \\
\end{array}$} \\
\hline (1) Model Weather Vars Linearly: & 1.46 & $(0.97)$ & 4.5 \\
\hline (2) Model Weather Vars with Cubics: & 4.74 & (3.91) & 14.7 \\
\hline (3) Model Weather Vars with Indicator Variables: & 0.95 & $(1.94)$ & 2.9 \\
\hline (4) Minimize the Influence of Outliers: & -1.32 & $(1.51)$ & -4.1 \\
\hline (5) Fully Interacted by State: & -0.94 & $(12.37)$ & -2.9 \\
\hline (6) Irrigation Cutoff $=5 \%$ : & 1.01 & $(1.48)$ & 3.1 \\
\hline (7) Irrigation Cutoff = 15\%: & 1.40 & $(1.56)$ & 4.3 \\
\hline (8) Assume Equal Weather Coefficients in Dryland and Irrigated Counties: & 1.26 & $(1.64)$ & 3.9 \\
\hline (9) Growing Season = April-October: & 0.65 & $(2.03)$ & 2.0 \\
\hline (10) Two Growing Seasons, April-September and October-March: & -1.80 & $(5.62)$ & -5.6 \\
\hline (11) Unweighted Regression: & -2.15 & $(4.12)$ & -6.7 \\
\hline \multicolumn{4}{|l|}{ [B] Impacts on Farm Revenues, Expenditures, and Government Payments } \\
\hline Farm Revenues: & 1.14 & $(2.96)$ & 3.5 \\
\hline Farm Expenditures: & 0.05 & $(2.36)$ & 0.1 \\
\hline Government Pavments: & 0.48 & $(0.22)$ & 1.5 \\
\hline
\end{tabular}

Notes: All dollar figures in billions of 2002 constant dollars. The entries report predicted impacts of climate change on agricultural profits using the estimation results from alternative versions of equation (4) and the Hadley 2 Long Run climate change scenario. All versions of equation (4) include controls for soil productivity and county and state by year fixed effects. The impacts' heteroskedastic consistent standard errors are in parentheses. The "Percent Effect" column reports the predicted change as a percent of mean annual agricultural profits in the 1987-2002 period. See Tables 6A and $6 \mathrm{~B}$, as well as the text for further details. 
TABLE 8: FiXed-EFFECTS ESTIMATES OF HADLEY 2 LONG Run CLIMATE CHANGE SCENARIO ON Agricultural PROFIT MOdELS, By STATE

\begin{tabular}{|c|c|c|c|c|}
\hline \multicolumn{5}{|c|}{ Predicted Impact on State Agricultural Profits (Largest to Smallest) } \\
\hline $\begin{array}{l}\text { State } \\
(1 \mathrm{a})\end{array}$ & $\begin{array}{c}\text { Billions of \$s } \\
(1 \mathrm{~b})\end{array}$ & $\begin{array}{l}\text { Std Error } \\
\text { (1c) }\end{array}$ & $\begin{array}{l}\text { State } \\
(2 a)\end{array}$ & $\begin{array}{c}\text { Percent } \\
(2 \mathrm{~b})\end{array}$ \\
\hline Pennsylvania & 0.57 & $(0.25)$ & W est Virginia & 276.5 \\
\hline South Dakota & 0.54 & $(0.03)$ & Wyoming & 270.5 \\
\hline Nevada & 0.51 & $(0.84)$ & Utah & 216.9 \\
\hline Arizona & 0.44 & $(0.73)$ & South Carolina & 181.5 \\
\hline Wyoming & 0.43 & $(0.34)$ & New Jersey & 146.0 \\
\hline South Carolina & 0.40 & $(0.17)$ & Nevada & 107.4 \\
\hline Georgia & 0.37 & $(0.58)$ & Arizona & 107.3 \\
\hline Utah & 0.36 & $(0.47)$ & South Dakota & 81.5 \\
\hline W ashington & 0.34 & $(0.63)$ & Pennsylvania & 65.2 \\
\hline New York & 0.24 & $(0.08)$ & Louisiana & 53.4 \\
\hline Kentucky & 0.20 & $(0.20)$ & Georgia & 49.8 \\
\hline Louisiana & 0.18 & $(0.43)$ & New York & 44.9 \\
\hline Oregon & 0.15 & $(0.36)$ & W ashington & 37.6 \\
\hline West Virginia & 0.12 & $(0.13)$ & New Mexico & 31.5 \\
\hline Minnesota & 0.10 & $(0.11)$ & Delaware & 30.1 \\
\hline New Mexico & 0.08 & $(0.04)$ & Oregon & 28.8 \\
\hline North Dakota & 0.05 & $(0.05)$ & Kentucky & 25.4 \\
\hline Missouri & 0.04 & $(0.04)$ & Rhode Island & 20.0 \\
\hline Indiana & 0.04 & $(0.10)$ & North Dakota & 12.7 \\
\hline Delaware & 0.03 & $(0.01)$ & Minnesota & 8.0 \\
\hline Michigan & 0.02 & $(0.03)$ & Virginia & 7.1 \\
\hline New Jersey & 0.02 & $(0.02)$ & Indiana & 6.2 \\
\hline Massachusetts & 0.01 & $(0.00)$ & Massachusetts & 5.6 \\
\hline Maryland & 0.01 & $(0.04)$ & Missouri & 5.5 \\
\hline Virginia & 0.01 & $(0.05)$ & Michigan & 4.4 \\
\hline Rhode Island & 0.00 & $(0.00)$ & Maryland & 2.5 \\
\hline Connecticut & 0.00 & $(0.00)$ & Connecticut & -4.2 \\
\hline New Hampshire & -0.01 & $(0.01)$ & W isconsin & -5.1 \\
\hline Vermont & -0.01 & $(0.01)$ & Texas & -6.2 \\
\hline Maine & -0.03 & $(0.03)$ & Ohio & -7.8 \\
\hline Tennessee & -0.04 & $(0.07)$ & Tennessee & -9.7 \\
\hline Ohio & -0.05 & $(0.08)$ & Iowa & -11.5 \\
\hline Alabama & -0.07 & $(0.19)$ & Florida & -13.1 \\
\hline Wisconsin & -0.07 & $(0.05)$ & Alabama & -14.6 \\
\hline Texas & -0.10 & $(0.94)$ & Illinois & -16.0 \\
\hline Montana & -0.12 & $(0.07)$ & Vermont & -17.7 \\
\hline Iowa & -0.13 & $(0.16)$ & Nebraska & -21.2 \\
\hline Idaho & -0.14 & $(0.19)$ & North Carolina & -22.6 \\
\hline Arkansas & -0.20 & $(0.40)$ & Arkansas & -23.2 \\
\hline Florida & -0.20 & $(0.27)$ & Idaho & -23.7 \\
\hline Illinois & -0.24 & $(0.18)$ & Kansas & -24.5 \\
\hline Mississippi & -0.25 & $(0.27)$ & New Hampshire & -29.4 \\
\hline Kansas & -0.30 & $(0.14)$ & Maine & -39.1 \\
\hline North Carolina & -0.32 & $(0.14)$ & Montana & -39.4 \\
\hline Nebraska & -0.35 & $(0.28)$ & California & -47.6 \\
\hline Oklahoma & -0.58 & $(0.88)$ & Missouri & -67.9 \\
\hline Colorado & -0.61 & $(0.64)$ & Colorado & -106.5 \\
\hline California & -2.40 & (1.64) & Oklahoma & -136.8 \\
\hline
\end{tabular}

Notes: All Figures in billions of 2002 constant dollars. The entries report state-level predicted impacts of climate change on agricultural profits using the estimation results from state-level versions of equation (4) and the Hadley 2 Long Run climate change scenario. Growing season degree days and total precipitation are modeled with quadratics and their effects are allowed to vary in irrigated an dryland counties. The specification also includes controls for soil productivity and county and year fixed effects. There are a total of 22 parameters so this model cannot be estimated separately for the 11 states with fewer than 22 counties in our sample. Instead, we group these states together in 2 groups (AZ, NV) and (CT, DE, MA, MD, ME, NH, NJ, RI, VT) and estimate the model separately for each group. See the text for more details. 
TABLE 9: FIXED-EFFECTS Estimates OF AGRICUltURAL Yield MODELS

\begin{tabular}{|c|c|c|c|c|c|c|}
\hline & \multicolumn{2}{|c|}{ Corn for Grain } & \multicolumn{2}{|c|}{ Soybeans } & \multicolumn{2}{|c|}{ Wheat for Grain } \\
\hline & $(1 \mathrm{a})$ & $(1 b)$ & $(2 a)$ & $(2 b)$ & $(3 a)$ & $(3 b)$ \\
\hline U.S. Total Value (Billion Dollars) & 21.64 & 21.64 & 10.10 & 10.10 & 8.21 & 8.21 \\
\hline County Mean of Dep. Variable & 85.63 & 85.63 & 31.72 & 31.72 & 2.96 & 2.96 \\
\hline U.S. Total Yield (Billion Bushels) & 8.69 & 8.69 & 2.39 & 2.39 & 2.17 & 2.17 \\
\hline \multicolumn{7}{|c|}{ Predicted Impact of Hadley 2 Long Term (2070-2099) Scenario on Crop Yields } \\
\hline All Counties: & $\begin{array}{c}-0.290 \\
(0.100)\end{array}$ & $\begin{array}{c}-0.110 \\
(0.080)\end{array}$ & $\begin{array}{l}-0.101 \\
(0.028)\end{array}$ & $\begin{array}{l}-0.012 \\
(0.019)\end{array}$ & $\begin{array}{c}0.268 \\
(0.082)\end{array}$ & $\begin{array}{c}0.021 \\
(0.066)\end{array}$ \\
\hline Percent of U.S. Total Yield & -3.3 & -1.3 & -4.2 & -0.5 & 12.4 & 1.0 \\
\hline Dryland Counties: & $\begin{array}{l}-0.260 \\
(0.080)\end{array}$ & $\begin{array}{l}-0.100 \\
(0.060)\end{array}$ & $\begin{array}{l}-0.076 \\
(0.017)\end{array}$ & $\begin{array}{l}-0.012 \\
(0.013)\end{array}$ & $\begin{array}{c}0.281 \\
(0.076)\end{array}$ & $\begin{array}{c}0.034 \\
(0.057)\end{array}$ \\
\hline Irrigated Counties: & $\begin{array}{l}-0.030 \\
(0.050)\end{array}$ & $\begin{array}{l}-0.010 \\
(0.050)\end{array}$ & $\begin{array}{l}-0.025 \\
(0.020)\end{array}$ & $\begin{array}{c}0.000 \\
(0.012)\end{array}$ & $\begin{array}{l}-0.013 \\
(0.025)\end{array}$ & $\begin{array}{l}-0.014 \\
(0.028)\end{array}$ \\
\hline Impact of Change in Temperature & $\begin{array}{l}-0.450 \\
(0.090)\end{array}$ & $\begin{array}{l}-0.210 \\
(0.080)\end{array}$ & $\begin{array}{l}-0.155 \\
(0.027)\end{array}$ & $\begin{array}{l}-0.047 \\
(0.018)\end{array}$ & $\begin{array}{c}0.258 \\
(0.082)\end{array}$ & $\begin{array}{c}0.015 \\
(0.066)\end{array}$ \\
\hline Impact of Change in Precipitation & $\begin{array}{c}0.170 \\
(0.050)\end{array}$ & $\begin{array}{c}0.100 \\
(0.040)\end{array}$ & $\begin{array}{c}0.053 \\
(0.011)\end{array}$ & $\begin{array}{c}0.035 \\
(0.010)\end{array}$ & $\begin{array}{c}0.010 \\
(0.009)\end{array}$ & $\begin{array}{c}0.006 \\
(0.009)\end{array}$ \\
\hline Soil Controls & Yes & Yes & Yes & Yes & Yes & Yes \\
\hline County Fixed Effects & Yes & Yes & Yes & Yes & Yes & Yes \\
\hline Year Fixed Effects & Yes & No & Yes & No & Yes & No \\
\hline State*Year Fixed Effects & No & Yes & No & Yes & No & Yes \\
\hline
\end{tabular}

Notes: "U.S. Total Value” is expressed in billions of 2002 constant dollars. The row "County Mean of Dependent Variable” is expressed in bushels per acre and "U.S. Total Yield" is in billions of bushels. The other entries report predicted impacts of climate change on crop output (in billions of bushels) using the estimation results from versions of equation (4) and the Hadley 2 Long Run climate change scenario. In the versions of equation (4), the dependent variables are county-level total bushels of production per acre planted (production / acre planted) for corn for grain, soybeans, and wheat for grain. The independent variables of interest are growing season degree days and precipitation, both of which are modeled with a quadratic and allowed to vary among dryland and irrigated counties. The regressions all include controls for soil characteristics and county fixed effects and are weighted by the square root of the number of acres planted for the relevant crop. Due to the nonlinear modeling of the weather variables, each county's predicted change in bushels per acre is calculated as the discrete difference in per acre output at the county's predicted degree days and precipitation after climate change and its current climate (i.e., the average over the 19702000 period). The resulting change in bushels per acre is multiplied by the number of acres of farmland in the county and then the national effect is obtained by summing across all counties in the sample. There are 5,992 observations in columns 1a and 1b; 4,320 in columns $2 \mathrm{a}$ and $2 \mathrm{~b}$; and 5,552 in columns 3a and $3 \mathrm{~b}$. 
Figure 1: TheOretical Relationship Between Profits Per ACRE AND TeMPerature

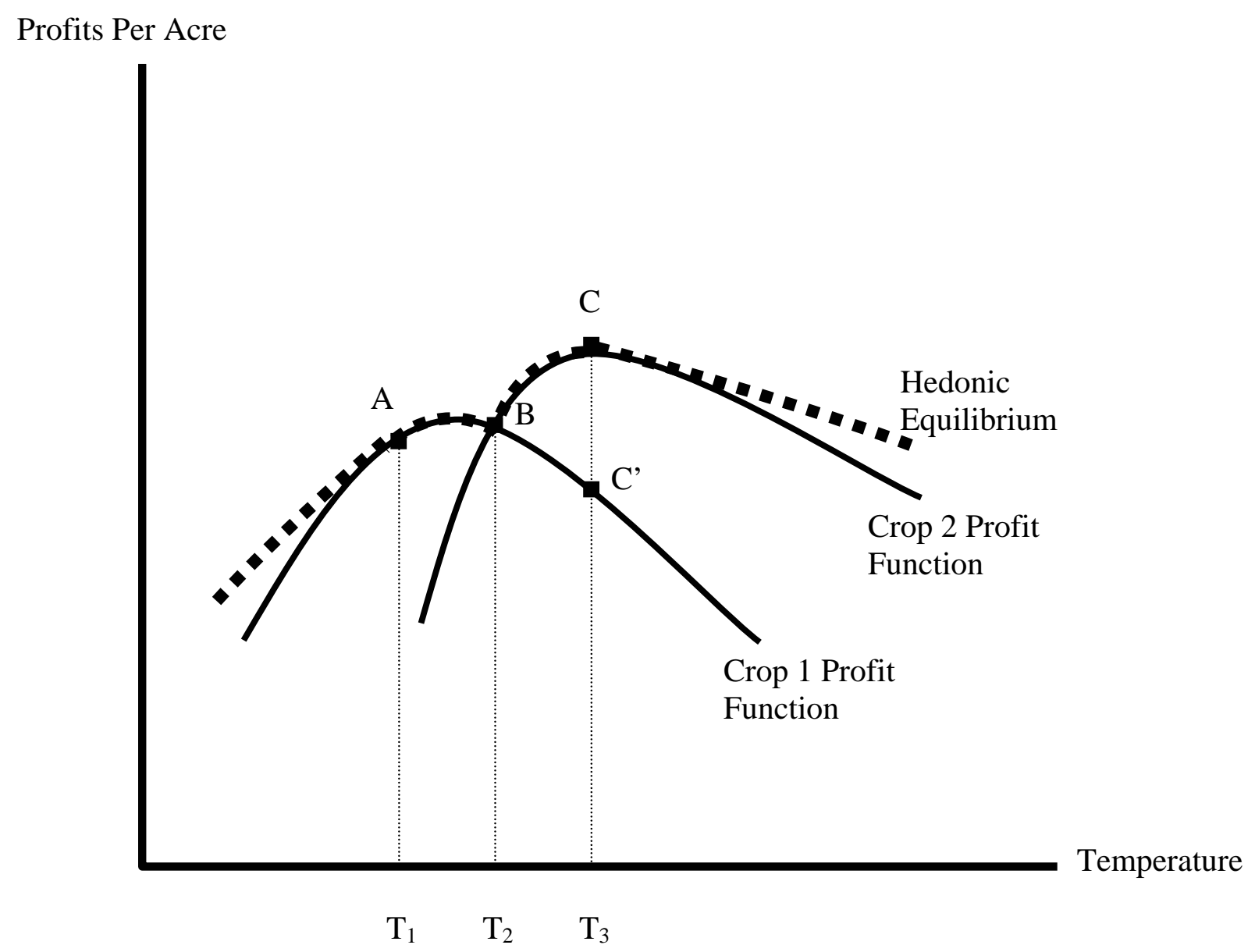


Figure 2A: AVERAGE GROWING SEASON DEgREE DAYS, By COUNTY 1970-2000

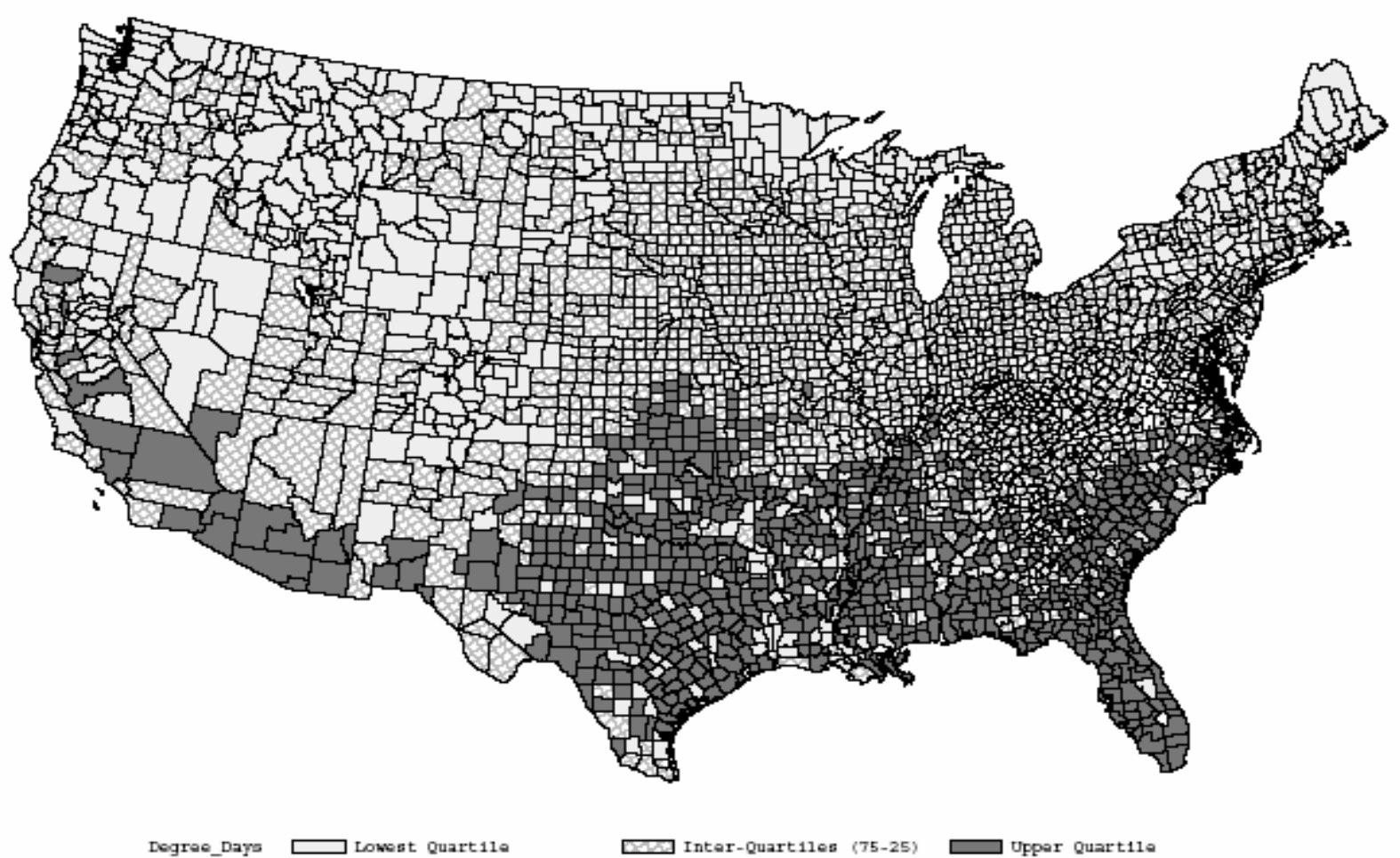

Figure 2B: Average Growing SeAson Total Precipitation, By CounTy 1970-2000

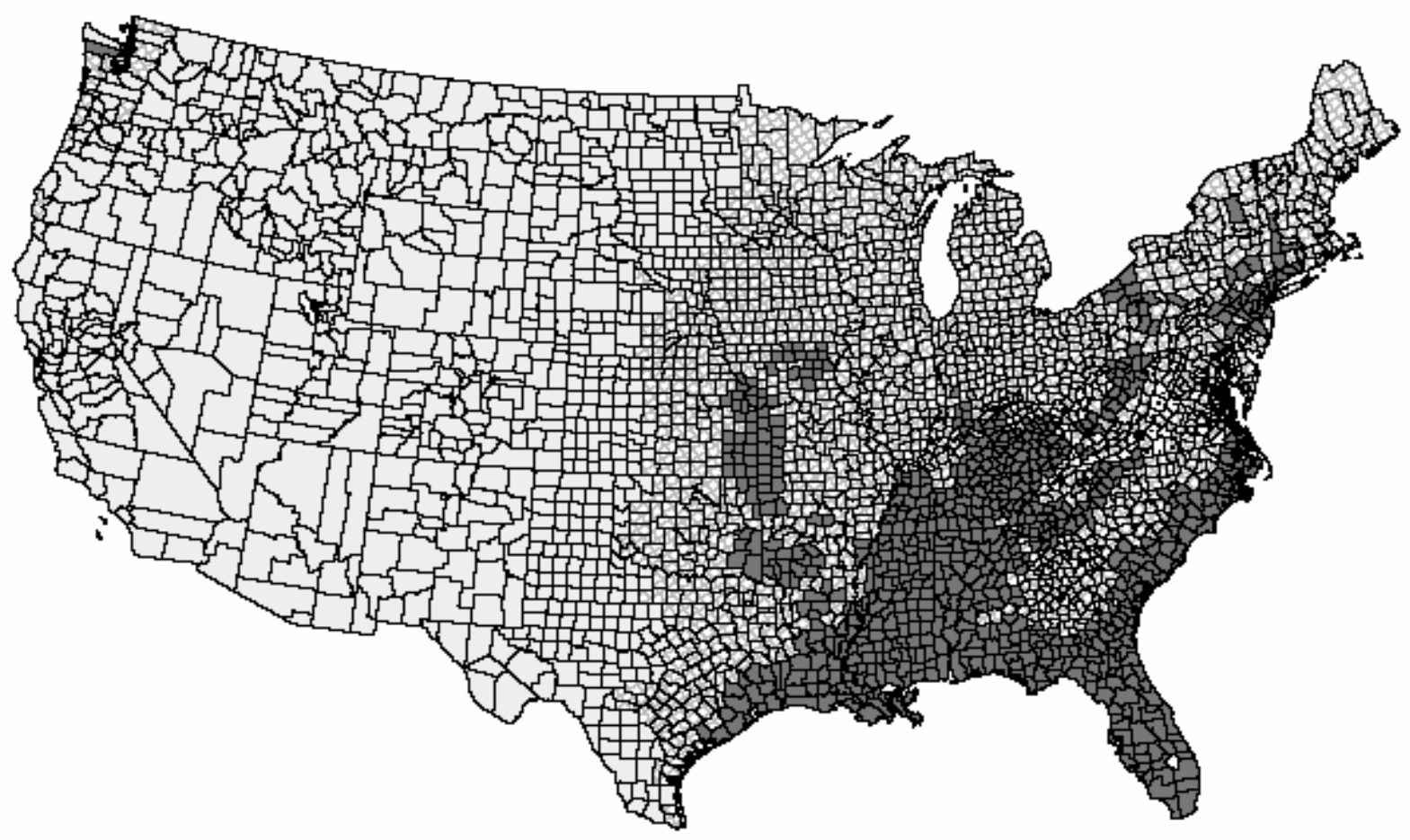


FIGURE 2C: AVERAGE PROFIT PER ACRE, BY COUNTY 1987-2002

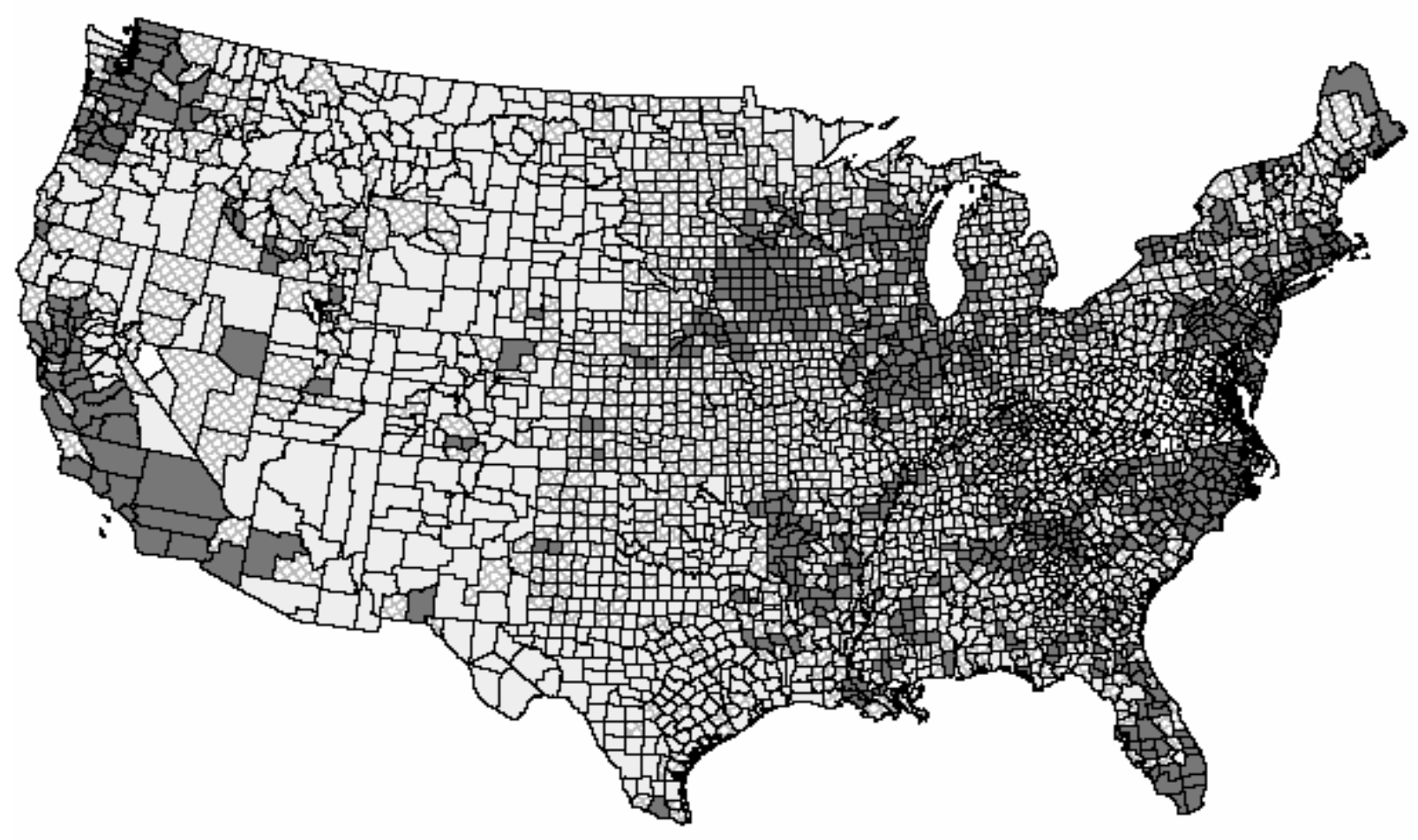

Drof1t_Der_Acre $\square$ Lowest Quart11e $\square$ Inter-Quart11es (75-25) $\square$ Opper Quart11e

Notes: See the text for details on how counties were divided into the categories for Figures 2A, 2B, and 2C. 


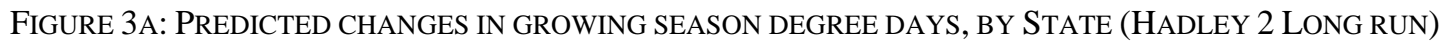

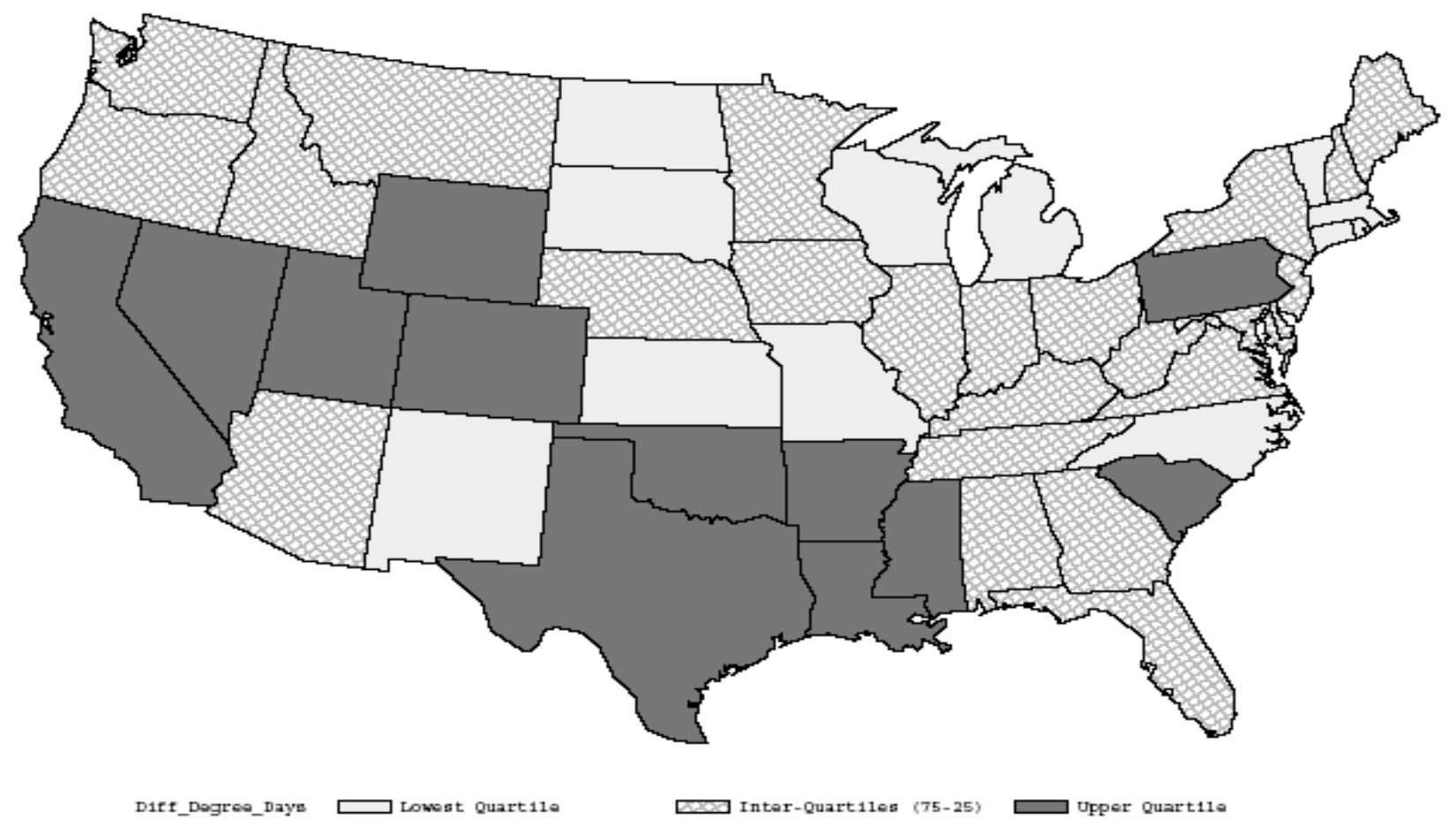

Figure 3B: Predicted changes in growing SeAson Precipitation, by State (Hadley 2 Long Run)

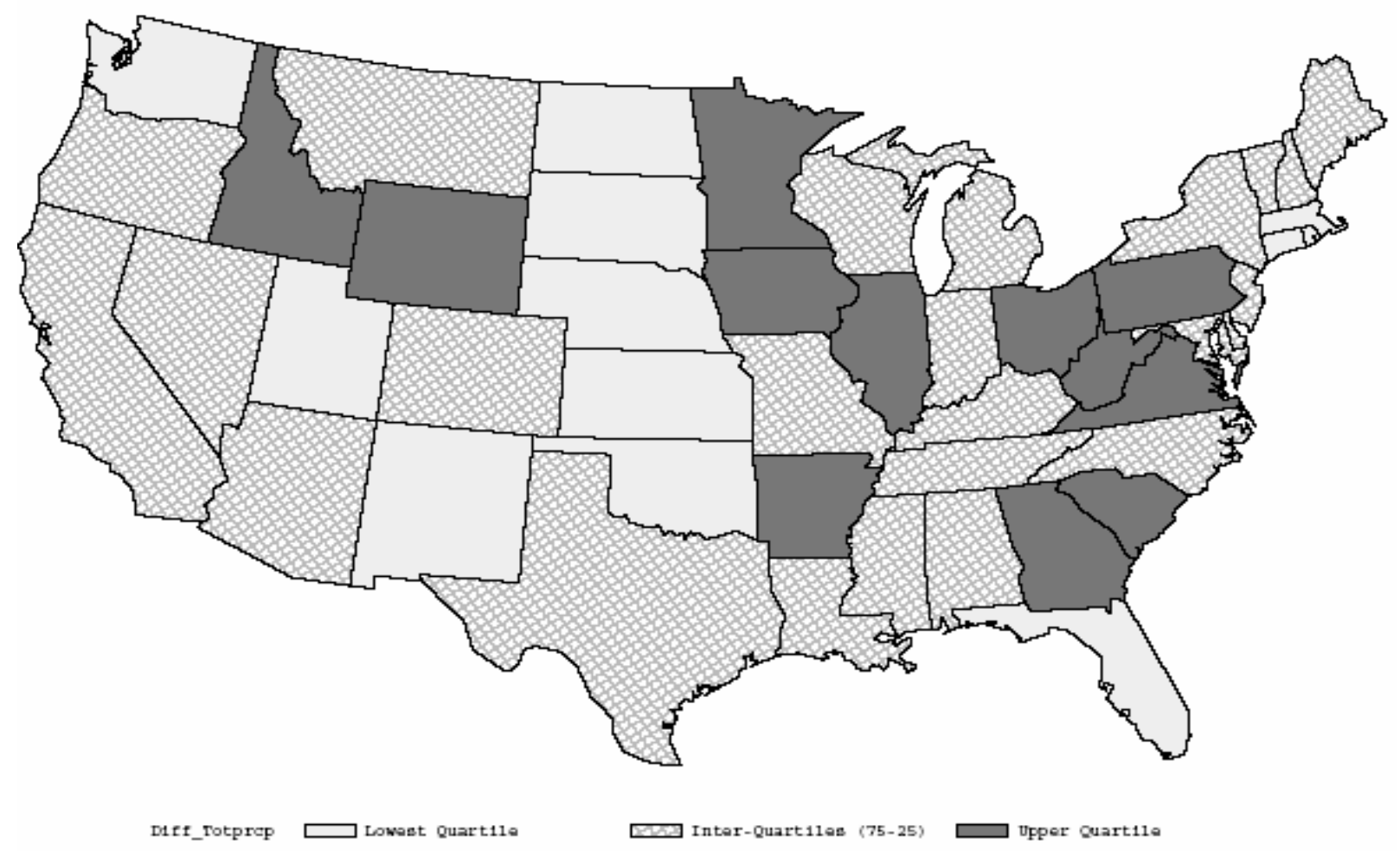

Notes: See the text for details on how counties were divided into the categories for Figures 3A and 3B. 


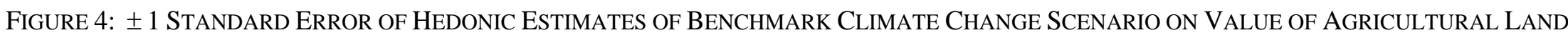

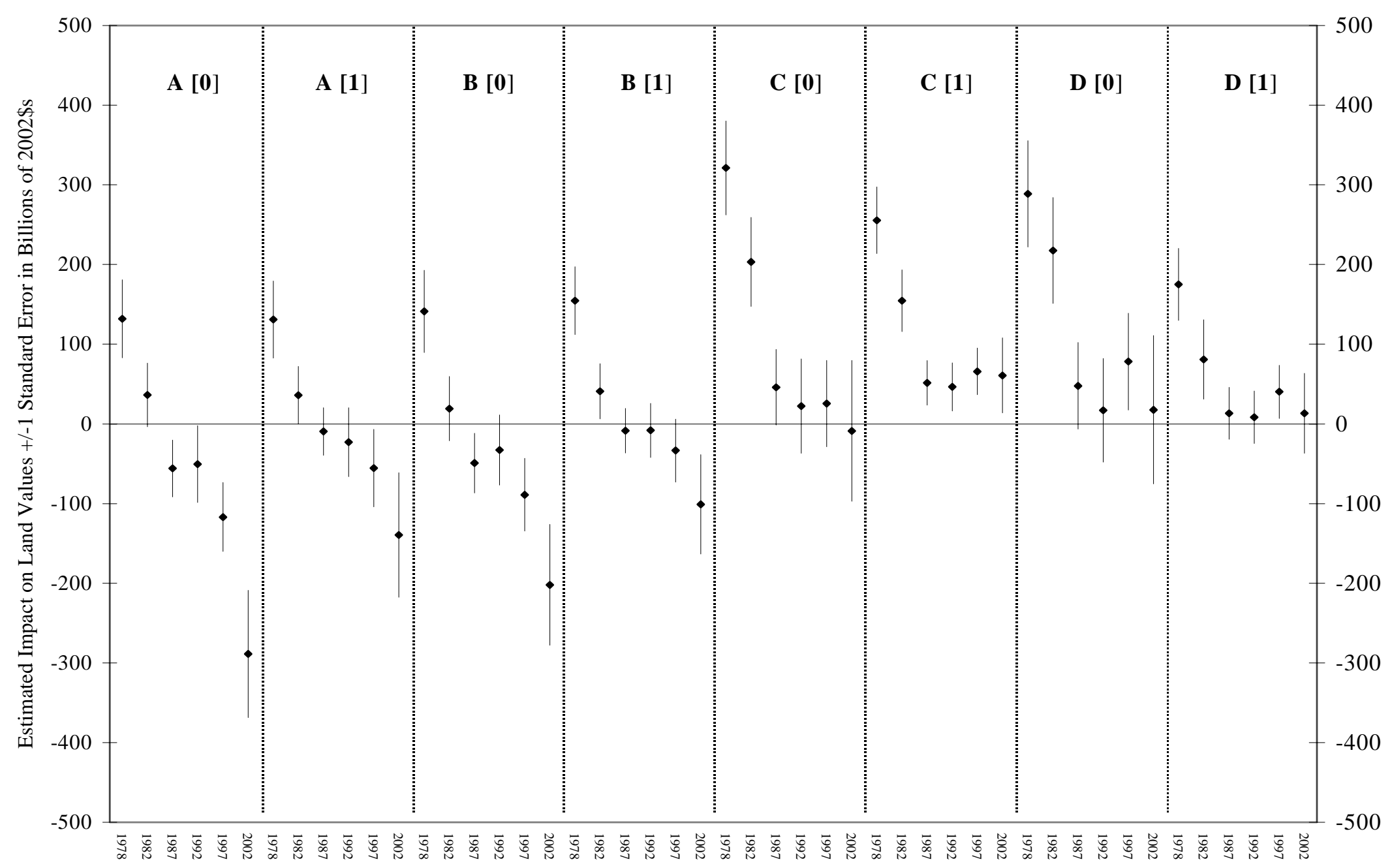

Notes: All dollar values are in 2002 constant dollars. Each line represents one of the 48 single year hedonic estimates of the impact of the benchmark increases of 5 degrees Fahrenheit and $8 \%$ precipitation from Table 5. The midpoint of each line is the point estimate and the top and bottom of the lines are calculated as the point estimate plus and minus one standard error of the predicted impact, respectively. See the text for further details. 
Figure 5A: Estimated Relationship Between Profits per Acre \& Growing Season Degree Days

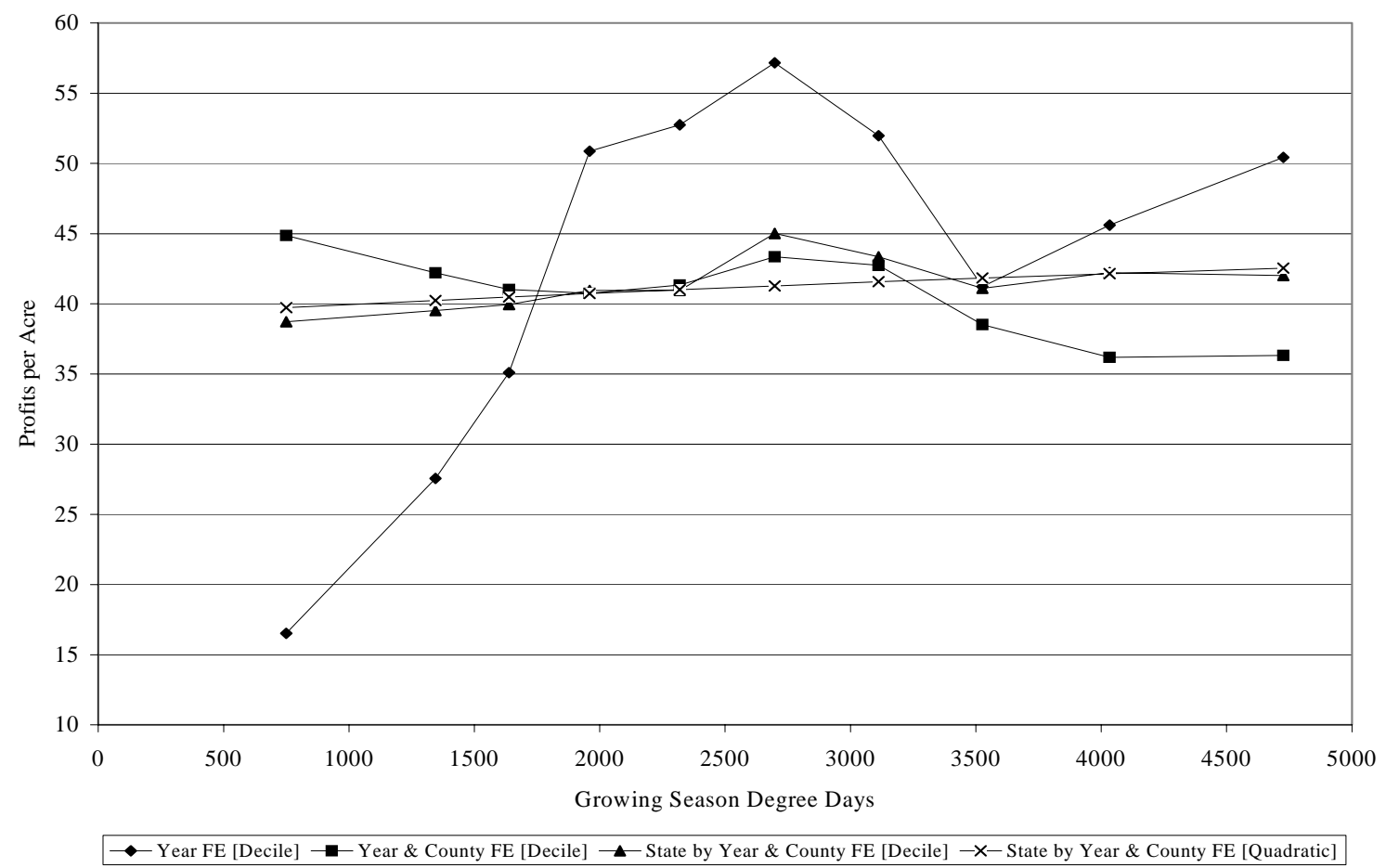

Notes: The figure plots the results from 4 separate regressions for county-level profits per acre all of which are weighted by total agricultural acres. The line "Year FE [Decile]" plots the parameter estimates on indicator variables for deciles of the distribution of growing season degree days at the midpoint of each decile's range. As the title of the line indicates, this regression also includes year fixed effects. The "Year \& County FE [Decile]" and "State by Year \& County FE [Decile]" lines repeat this exercise but include year and county fixed effects and state by year and county fixed effects, respectively. The "State by Year \& County FE [Quadratic]" line replaces the indicators variables with a quadratic in degree days and plots the conditional means at the midpoints of each decile's range.

Figure 5B: Estimated Relationship Between Profits Per Acre \& Growing Season Precipitation

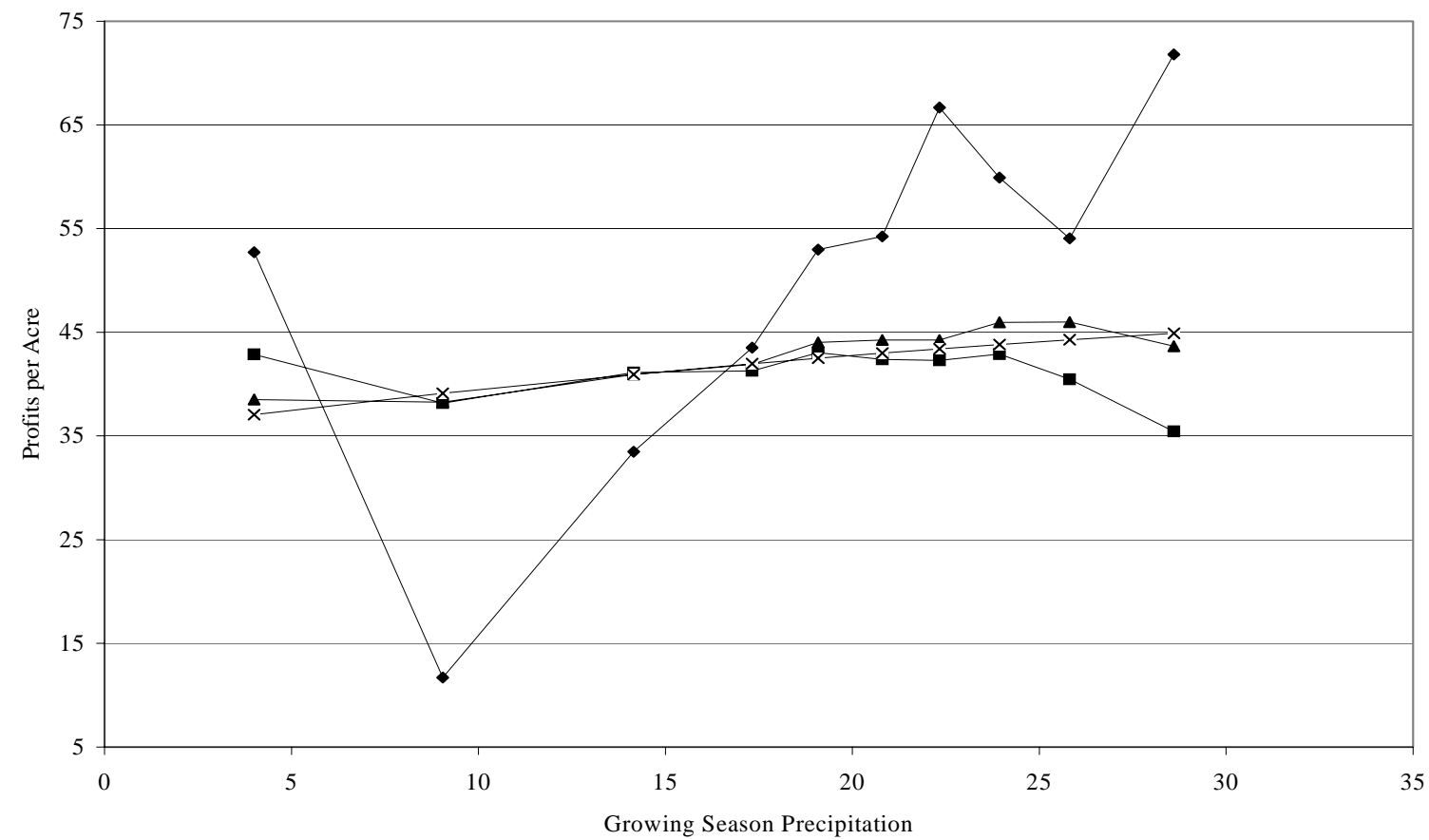

$\bullet-$ Year FE [Decile] $-\mathbf{-}$ Year \& County FE [Decile] $\multimap-$ State by Year \& County FE [Decile] $-\mathbf{x}-$ State by Year \& County FE [Quadratic]

Notes: This figure replicates the graphical exercise in 5A, except for growing season precipitation (rather than growing season degree days). 
Figure 6: Predicted Impact of Climate Change on State-Level Agricultural Profits, Hadley 2 LONG RUN SCENARIO

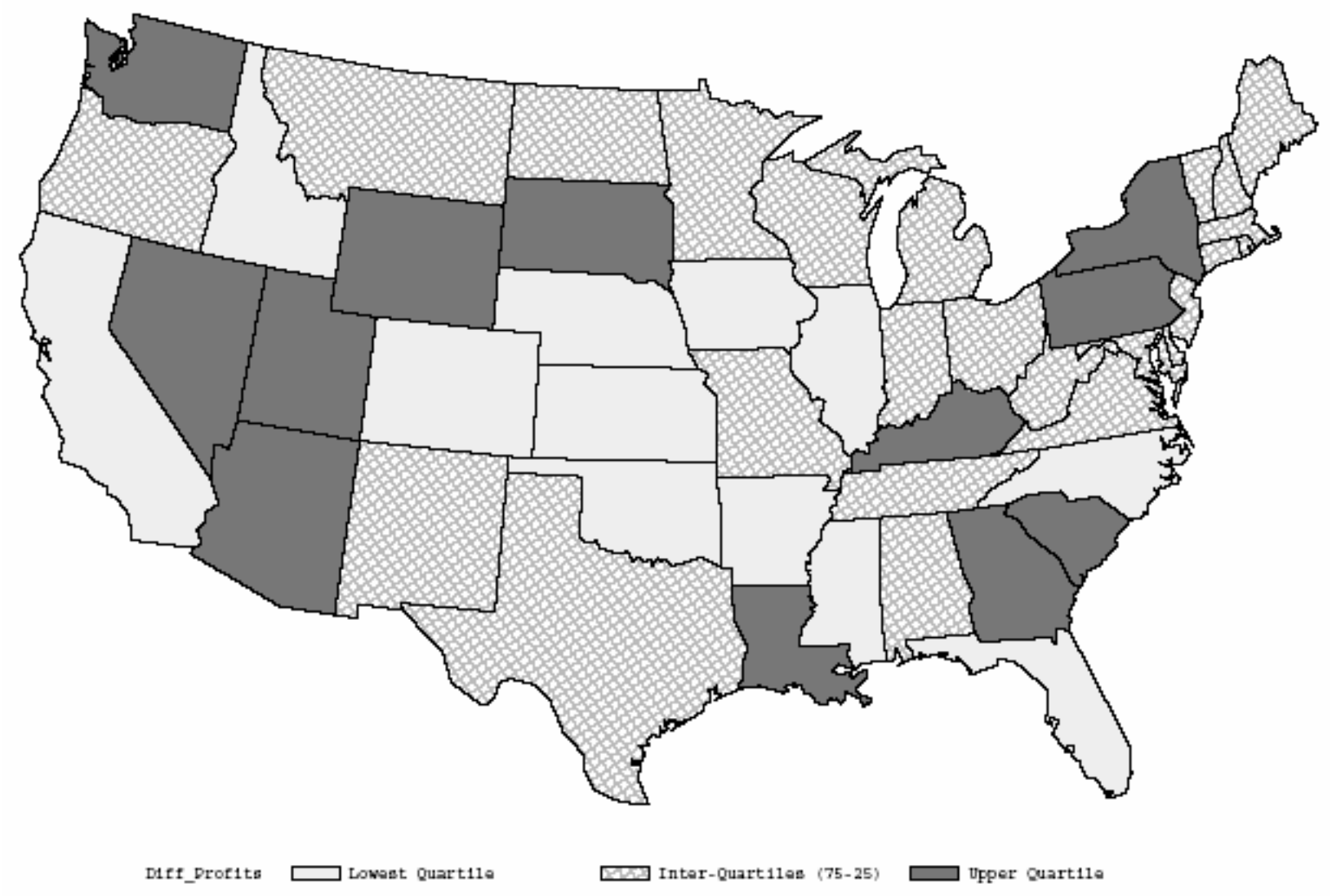

Notes: See the text for details on how counties were divided into the three categories. 